\title{
Clear-sky closure studies of lower tropospheric aerosol and water vapor during ACE-2 using airborne sunphotometer, airborne in-situ, space-borne, and ground-based measurements
}

\begin{abstract}
By BEAT SCHMID ${ }^{1 *}$, JOHN M. LIVINGSTON ${ }^{2}$, PHILIP B. RUSSELL ${ }^{3}$, PHILIP A. DURKEE ${ }^{4}$, HAFLIDI H. JONSSON ${ }^{4}$, DONALD R. COLLINS ${ }^{5 \S}$, RICHARD C. FLAGAN ${ }^{5}$, JOHN H. SEINFELD $^{5}$, SANTIAGO GASSÓ ${ }^{6}$, DEAN A. HEGG ${ }^{6}$, ELISABETH ÖSTRÖM ${ }^{7 \dagger}$, KEVIN J. NOONE ${ }^{7}$, ELLSWORTH J. WELTON ${ }^{8 \ddagger}$, KENNETH J. VOSS ${ }^{8}$, HOWARD R. GORDON ${ }^{8}$, PAOLA FORMENTI $^{9}$ and MEINRAT O. ANDREAE 9 , ${ }^{1}$ Bay Area Environmental Research Institute, San Francisco, CA, USA; ${ }^{2}$ SRI International, Menlo Park, CA, USA $;{ }^{3} N A S A$ Ames Research Center, Moffett Field, CA, USA; ${ }^{4}$ Naval Postgraduate School, Monterey, CA, USA; ${ }^{5}$ California Institute of Technology, Pasadena, CA, USA; ${ }^{6}$ University of Washington, Seattle, WA, USA; ${ }^{7}$ Meteorological Institute, Stockholm University, Stockholm, Sweden; ${ }^{8}$ University of Miami, Miami, FL, USA; ${ }^{9}$ Max Planck Institute for Chemistry, Mainz, Germany
\end{abstract}

(Manuscript received 28 December 1998; in final form 4 October 1999)

\section{ABSTRACT}

We report on clear-sky column closure experiments (CLEARCOLUMN) performed in the Canary Islands during the second Aerosol Characterization Experiment (ACE-2) in June/July 1997. We present CLEARCOLUMN results obtained by combining airborne sunphotometer and in-situ (optical particle counter, nephelometer, and absorption photometer) measurements taken aboard the Pelican aircraft, space-borne NOAA/AVHRR data and ground-based lidar and sunphotometer measurements. During both days discussed here, vertical profiles flown in cloud-free air masses revealed 3 distinctly different layers: a marine boundary layer (MBL) with varying pollution levels, an elevated dust layer, and a very clean layer between the MBL and the dust layer. A key result of this study is the achievement of closure between extinction or layer aerosol optical depth (AOD) computed from continuous in-situ aerosol size-distributions and composition and those measured with the airborne sunphotometer. In the dust, the agreement in layer AOD $(\lambda=380-1060 \mathrm{~nm})$ is $3-8 \%$. In the MBL there is a tendency for the in-situ results to be slightly lower than the sunphotometer measurements $(10-17 \%$ at $\lambda=525 \mathrm{~nm})$, but these differences are within the combined error bars of the measurements and computations.

* Corresponding author address: MS-245, NASA Ames Research Center, Moffett Field, CA, 94035-1000, USA.

e-mail: bschmid@mail.arc.nasa.gov

${ }^{\dagger}$ Now at Meteorological Office, Hadley Centre, Bracknell, UK.

${ }^{\ddagger}$ Now at Science Systems and Applications Inc., Greenbelt, MD, USA.

${ }^{\S}$ Now at Texas A\&M University, College Station,

TX, USA. 


\section{Introduction}

The second Aerosol Characterization Experiment (ACE-2) of the International Global Atmospheric Chemistry Project (IGAC) ran from 16 June to 25 July 1997 . The results presented in this study are part of the "Clear-sky column closure experiment" (CLEARCOLUMN) activity, one of 7 ACE-2 activities (Raes et al., 2000). Clearsky column closure experiments call for characterization of aerosol layers by simultaneous measurements using different techniques that can be related using models (Quinn et al., 1996). During ACE-2, several CLEARCOLUMN experiments involving different platforms were carried out successfully (Russell and Heintzenberg, 2000). In this paper, we report on CLEARCOLUMN results obtained by combining airborne sunphotometer and in-situ measurements taken aboard the Pelican aircraft, space-borne NOAA/AVHRR data and ground-based lidar and sunphotometer measurements.

A wide range of aerosol types was encountered throughout the ACE-2 area, including background Atlantic marine, European pollution-derived, and African mineral dust. Of the 21 flights performed by the Pelican in ACE-2, 5 were designed as CLEARCOLUMN missions. In this study we report on Pelican flights tf 15 and tf 20 performed on 8 and 17 July 1997. On both days, vertical profiles flown in cloud-free air masses revealed 3 distinctly different layers: a marine boundary layer (MBL) with varying pollution levels, an elevated dust layer and a very clean layer between the MBL and the dust layer.

\section{Measurements}

\subsection{Airborne measurements}

2.1.1. The Pelican aircraft. The Pelican is operated by the Marina, California based Center for Interdisciplinary Remotely-Piloted Aircraft Studies (CIRPAS) (Bluth et al., 1996). The Pelican, a highly modified Cessna 337 Skymaster, was the smallest of the 6 aircraft participating in ACE-2. For a complete list of the Pelican ACE-2 payload, see Russell and Heintzenberg (2000). The Pelican has the option to be piloted remotely; however, on all flights performed during ACE-2 out of the north airport of Tenerife $\left(28.48^{\circ} \mathrm{N}, 16.34^{\circ} \mathrm{W}\right.$,
$632 \mathrm{~m}$ ) it was flown by 2 on-board pilots. The typical cruising speed was about $50 \mathrm{~m} \mathrm{~s}^{-1}$, and the maximum flight altitude was close to $4000 \mathrm{~m}$.

2.1.2. The NASA Ames Airborne Tracking 14-channel Sunphotometer (AATS-14). AATS-14 measures the transmission of the direct solar beam in 14 spectral channels ( 380 to $1558 \mathrm{~nm}$ ). Azimuth and elevation motors controlled by a differential sun sensor rotate a tracking head to lock on to the solar beam and keep detectors normal to it. The tracking head mounts outside the aircraft skin, to minimize blockage by aircraft structures and to avoid data contamination by aircraftwindow effects. Each channel consists of a baffled entrance path, interference filter, photodiode detector, and integral preamplifier. The filter/ detector/preamp sets are temperature controlled to avoid thermally induced calibration changes. Data are digitized and recorded by a self-contained data acquisition and control system. Radiometric calibration is determined via Langley plots (Schmid and Wehrli, 1995), either at high-mountain observatories or during specially designed flights. The first science flights of AATS-14 were made on the Pelican during the Tropospheric Aerosol Radiative Forcing Observational Experiment (TARFOX) in July 1996 (Russell et al., 1999a and 1999b). AATS-14 is an extended version of the 1985-built AATS-6 instrument (Matsumoto et al., 1987). After having been operated on a variety of aircraft or at land-based sites during all previous missions, AATS- 6 was operated on board a ship - the R/V Vodyanitskiy — during ACE-2. These results are presented by Livingston et al. (2000).

Our methods for data reduction, calibration, and error analysis have been described previously (Russell et al., 1993; Schmid and Wehrli, 1995; Schmid et al., 1996, 1997, 1998). A very brief summary is given here: the AATS-14 channels are chosen to allow separation of aerosol, water vapor, and ozone transmission. From these slant-path transmissions we retrieve spectral aerosol optical depth (AOD) in 13 narrow wavelength bands and the columnar amounts of water vapor (CWV) and ozone. For the results shown here the ozone retrieval was turned off and the total column ozone values were taken from the Total Ozone Monitor Sensor (TOMS) on the Earth Probe satellite. In addition to the usual corrections for Rayleigh scattering, $\mathrm{O}_{3}$ and $\mathrm{NO}_{2}$ absorption, some 
channels required corrections for $\mathrm{H}_{2} \mathrm{O}$ and $\mathrm{O}_{2}-\mathrm{O}_{2}$ (Michalsky et al., 1999) absorption.

During ACE-2, AATS-14 acquired data of good quality during 14 of 21 flights. Maximum (but constant) altitude flights during sunset allowed us to perform 3 successful in-flight Langley-plot calibrations of AATS-14. In addition, 2 months before ACE- 2 a calibration consisting of 6 Langley plots had been performed at Mauna Loa Observatory in Hawaii. The averaged calibration constants obtained at Mauna Loa and during ACE-2 differed by 0.2 to $1.6 \%$ depending on wavelength The uncertainty of the retrieved AOD due to uncertainties in calibration, signal measurement, airmass computation, and corrections of molecular scattering and absorption, is computed according to Russell et al. (1993) and is smaller than 0.01 for the data presented here (see also Schmid et al., 1999). The uncertainty in CWV is computed according to Schmid et al. (1996) and is smaller than $0.2 \mathrm{~g} / \mathrm{cm}^{2}$.

The Pelican was able to fly as low as $20 \mathrm{~m}$ above the ocean surface, thus allowing measurement of the entire overlying atmospheric column. Having the Pelican fly narrow up or down spirals allowed us to retrieve vertical profiles of spectral AOD and CWV. Differentiation of those profiles leads to spectral aerosol extinction and water vapor density profiles. In the AATS-14 vertical profiles shown in this paper, occasionally the AOD or the CWV decreased (increased) when the plane descended (ascended). This is of course non-physical. However, this is a natural consequence of the facts that (1) the sunphotometer can only measure the transmittance of the sunphotometer-to-sun path, (2) that path in general passes through a horizontally inhomogeneous, time-varying atmosphere, and (3) the path and the atmosphere move with respect to each other as the plane moves and the wind blows. Before the sunphotometer AOD or the CWV profile is vertically differentiated to obtain extinction or $\mathrm{H}_{2} \mathrm{O}$ density, it needs to be smoothed (in a non-biased manner) to eliminate increases in AOD or CWV with height. In this study, smoothed spline fits have been used for this purpose. However, to avoid over-smoothing we occasionally allow the extinction or the $\mathrm{H}_{2} \mathrm{O}$ density to become slightly negative as it can be seen in Figs. 2, 4. The need for smoothing of AOD profiles prior to differentiation has been recognized by others and varying implementations have been chosen (Clarke et al., 1996; Hartley et al., 2000). It is noteworthy that the errors in AOD or CWV cancel out when the profiles are differentiated. We therefore estimate the error in aerosol extinction from the scatter in the AOD profile $(7 \%$ in the $\mathrm{MBL}, 4 \%$ in the dust) plus an uncertainty caused by the splining procedure $\left(0.005 \mathrm{~km}^{-1}\right)$.

Finally, we estimate aerosol size distributions by inverting AOD or extinction spectra using the constrained linear inversion method of King et al. (1978) (see also King (1982); Gonzàlez Jorge and Ogren (1996)). In its present formulation, the inversion assumes an aerosol consisting of homogeneous spherical particles which are nondispersive (i.e., refractive index independent of wavelength or size) over the wavelength range of the observations.

2.1.3. In-situ aerosol size distributions. A differential mobility analyzer (DMA) and 2 optical particle counters (OPC) on-board the Pelican provided continuous composite aerosol size distributions for diameters between 0.005 and $8 \mu \mathrm{m}$. The DMA system mounted in the nose of the Pelican was the Caltech Automated Classified Aerosol Detector (ACAD) (see Collins et al., 2000). The OPCs mounted on the wings of the Pelican were a passive cavity aerosol spectrometer probe (PCASP-100X) and a forward scattering spectrometer probe (FSSP-100) manufactured by PMS, Boulder, CO. The size range covered by each instrument was 0.005 to $\sim 0.2 \mu \mathrm{m} *$ for the ACAD, 0.15 to $\sim 3 \mu \mathrm{m}$ for the PCASP and 0.5 to $\sim 8 \mu \mathrm{m}$ for the FSSP.

Unfortunately, the Pelican FSSP was not operational during the 2 flights discussed here. Therefore, we extrapolated the PCASP size distribution by using the shape of the distribution expected based on FSSP measurements under similar conditions. For the marine boundary layer aerosol, the shape was taken from Pelican FSSP measurements during flights tf1 to tf12. Fortunately, the shape changed only moderately throughout these flights. For the dust aerosol, the shape was taken from FSSP measurements taken aboard the Merlin aircraft on 8 July 1997 (Brenguier et al., 2000). For details of this extrapolation procedure, see Collins et al. (2000).

We have combined the measurements of ACAD,

\footnotetext{
* All particle sizes in this paper refer to diameters.
} 
PCASP and FSSP into a consistent data set of time resolved size distributions of the ambient aerosol. The details of this procedure are described by Collins et al. (2000). An important step is correcting the PCASP sizing for the difference of the complex refractive index $m$ of the polystyrene latex spheres $(m=1.56-0 i)$ used for calibration versus that of the actually measured aerosol. (Note that the PCASP inlet is designed to minimize inertial particle losses, thereby enabling penetration and detection of particles exceeding $3 \mu \mathrm{m}$.) The other important issue is the potential growth or shrinkage of a hygroscopic particle if measured under non-ambient conditions (i.e., RH). The FSSP measures the aerosol particles at ambient conditions, and therefore no correction is necessary here. The sample stream reaching the ACAD was in general several ${ }^{\circ} \mathrm{C}$ above ambient, resulting in reduced $\mathrm{RH}$, and consequently partial evaporation of some particles. Also for the PCASP (even when the de-icing heaters remained off during ACE-2) combined ram and sheath air heating caused a heating of $\sim 3.5^{\circ} \mathrm{C}$ (equivalent to an $\mathrm{RH}$ decrease of 15-20\%). Adjusting for the differences in refractive index and $\mathrm{RH}$ requires knowledge of the chemical make-up of the individual particle, information that was not available at the same temporal and size resolution as the size measurements. Filter measurements were made on board the Pelican (Schmeling et al., 2000). However, because these samples were not size-resolved and often combined contributions from the free troposphere (FT) and the MBL, they only partly provided the necessary information. Therefore for each flight, size-resolved aerosol composition for the MBL and the FT was assumed using ground measurements (Putaud et al., 2000) made at 2 sites in Tenerife: Punte del Hidalgo (located at the northern end of the island at an elevation of $30 \mathrm{~m}$ ) and Izaña (in the central region of the island at $2367 \mathrm{~m}$ ).

Given the aerosol composition the response of the size distribution to changes in $\mathrm{RH}$ and $m$ can be deduced. The assumed compositions consist of sulfates $\left(\mathrm{H}_{2} \mathrm{SO}_{4}, \mathrm{NH}_{4} \mathrm{HSO}_{4}\right.$ and $\left.\left(\mathrm{NH}_{4}\right)_{2} \mathrm{SO}_{4}\right)$, sea salt, organic carbon (OC), elemental carbon (EC) and dust. Hygroscopic growth and $m$ of the salts was calculated using published data on solution thermodynamics (Tang and Munkelwitz, 1994; Tang 1996; Tang et al., 1997). The remaining components were assumed to be non-hygroscopic.
We assumed $m=1.96-0.66 i$ (Seinfeld and Pandis, 1998) for elemental carbon, $m=1.55-0.0 i$ (Larson et al., 1988) for organic carbon and $m=1.56-\left(0.17 \times 10^{-0.0025 \lambda(\mathrm{nm})}\right) i$ for dust (from Patterson et al., 1977). The complex refractive index of each of the aerosol constituents is assumed independent of wavelength. The only exception is the imaginary part of dust, where an equation fitted through the data (300 to $700 \mathrm{~nm}$ ) measured by Patterson et al. (1977) on Tenerife had been used. An external mixture of the salts and dust was assumed with most of the EC and OC assumed to be internally mixed (homogeneously) with the salt particles. Mie code was then used to calculate extinction $\left(\sigma_{\mathrm{e}}\right)$, scattering $\left(\sigma_{\mathrm{s}}\right)$, and absorption $\left(\sigma_{\mathrm{a}}\right)$, coefficients. A detailed error analysis of the resulting ambient aerosol size distributions and of the derived quantities is given by Collins et al. (2000). In this paper we will refer to these results as Caltech computations.

2.1.4. Nephelometers. We use aerosol particle scattering coefficients, $\sigma_{\mathrm{s}}$, measured by 3 separate integrating nephelometers aboard the Pelican. One of the 3 nephelometers was a TSI 3563 3-wavelength $(450,550$ and $700 \mathrm{~nm})$ integrating nephelometer (Öström and Noone, 2000) operated by the Meteorological Institute, Stockholm University, Sweden (MISU). The sample air used in this instrument was heated to $30-40^{\circ} \mathrm{C}$. The resulting sample $\mathrm{RH}$ was $35-45 \%$ in the MBL and $<10 \%$ in the FT. The resulting $\sigma_{\mathrm{s}}$ were smoothed by using a $30 \mathrm{~s}$ running average on the $1 \mathrm{~Hz}$ data. The other 2 nephelometers (Radiance Research, model M903, $\lambda=530 \mathrm{~nm}$ ) are part of the University of Washington Passive Humidifier (UW-PH) system (Gassó et al., 2000). One of them measured $\sigma_{\mathrm{s}}$ at typically $5^{\circ} \mathrm{C}$ above ambient conditions (sample $\mathrm{RH}=50-60 \%$ in the MBL, $10-20 \%$ in the FT) and the other had a humidity control that allowed measuring $\sigma_{\mathrm{s}}$ at an RH higher than ambient $(\mathrm{RH}=85-95 \%$ in the MBL, $50-95 \%$ in the FT). The data were averaged over $6 \mathrm{~s}$.

The fact that the 3 nephelometers measure $\sigma_{\mathrm{s}}$ (at the green common wavelength) at 3 different RH allows us to estimate $\sigma_{\mathrm{s}}$ at ambient $\mathrm{RH}$ from a statistical fit of the equation (Gassó et al., 2000).

$\sigma_{\mathrm{s}}(\mathrm{RH})=\sigma_{\mathrm{s}, \mathrm{RH}=0}\left[1-\frac{\mathrm{RH}}{100}\right]^{-\gamma}$. 
Beforehand the UW-PH 6-s $\sigma_{\mathrm{s}}$ data were smoothed to exhibit a similar smoothness as the MISU 30-s averages. The resulting $\gamma$ values were then used to estimate $\sigma_{\mathrm{s} \text {,amb }}$ at the 2 other wavelengths of the MISU nephelometer. This assumes $\gamma$ being wavelength independent. Before $\sigma_{\mathrm{s} \text {,amb }}$ was computed we applied 2 corrections to the nephelometer data.

Anderson et al. (1996) investigated the nonidealities in the light source as well as the truncation of near forward and near backward scattered light for the TSI 3563. Because no similar data are available for the Radiance Research nephelometers, their characteristics were assumed equivalent to the TSI instrument. Mie computations with the continuous size-distribution results described above and the resulting nephelometer angular sensitivity led to time resolved correction factors. The correction of the nephelometer non-idealities increases $\sigma_{\mathrm{s}}$ by a factor of 1.13-1.2 in the MBL and $1.3-1.5$ in the dust.

All 3 nephelometers sampled aerosol from a common isokinetic inlet mounted in front of the Pelican's nose. To obtain an upper size cut, the particles were pulled through a set of cyclone impactors with a nominal $50 \%$ cut-off at an aerodynamic diameter $D_{\mathrm{a}}=2.5 \mu \mathrm{m}$. According to Stern (1977) the geometric particle diameter, $D_{\mathrm{g}}$, is related to $D_{\mathrm{a}}$ by

$D_{\mathrm{g}}=\frac{D_{\mathrm{a}}}{\sqrt{\rho / \rho_{0}}}$,

where $\rho$ is the particle density and $\rho_{0}=1 \mathrm{~g} / \mathrm{cm}^{3}$. Based on Tang and Munkelwitz (1994), Tang (1996) and Tang et al. (1997), we estimate $\rho=$ $1.3 \mathrm{~g} / \mathrm{cm}^{3}$ for the MBL aerosol at $\mathrm{RH}=80 \%$. For the dust we use $\rho=2.65 \mathrm{~g} / \mathrm{cm}^{3}$ (Tegen and Fung, 1994). Hence, the geometric $50 \%$ cut-off diameter $D_{\mathrm{g}}$ is approximately $2.2 \mu \mathrm{m}$ in the MBL and $1.5 \mu \mathrm{m}$ in the dust. Mie computations with the continuous Caltech size-distribution results and an S-curve shaped cyclone penetration efficiency (centered at the appropriate $50 \%$ cut-off $D_{\mathrm{g}}$ ) led to time resolved correction factors. The correction of the nephelometer inlet cut-off effects increases $\sigma_{\mathrm{s}}(\lambda=450-700 \mathrm{~nm})$ by a factor of $1.17-1.47$ in the MBL and 2.8-3.2 in the dust.

The random error in the UW-PH and the MISU nephelometers was estimated $0.0025 \mathrm{~km}^{-1}$ by adjusting the value specified by Gassó et al. (2000) for 6-s averages $\left(0.005 \mathrm{~km}^{-1}\right)$ to the 30 -s averages, following the dependency indicated by Anderson et al. (1996). The combined uncertainty of the angular sensitivity and inlet cut-off correction is assumed to be $30 \%$. The uncertainty in interpolating $\sigma_{\mathrm{s}, \mathrm{amb}}$ using eq. (1) is estimated to be $<15 \%$ in the MBL (based on Gassó et al., 2000) and assumed negligible in the dust.

2.1.5. Particle soot/absorption photometer. The aerosol light absorption coefficient, $\sigma_{\mathrm{a}, \mathrm{dry}}$, at $565 \mathrm{~nm}$ was measured with a Radiance Research Particle Soot/Absorption Photometer (PSAP) operated by MISU (Öström and Noone, 2000). The instrument works on the basic principle of Beer's law in which the change in optical transmission of a filter caused by particle deposition is related to the optical absorption coefficient and a calibration transfer coefficient. The instrument can be operated continuously to get a time series of the aerosol absorption coefficient. The PSAP $\sigma_{\mathrm{a}, \mathrm{dry}}$ data have been corrected for scattering contributions by subtracting $3 \%$ of $\sigma_{\mathrm{s}, \mathrm{dry}}$ measured by the MISU nephelometer at the green wavelength (Öström and Noone, 2000). The particles sampled by the PSAP were pulled through the same set of cyclones and underwent the same heating as those measured by the MISU nephelometer. Mie computations with the continuous size-distribution results led to time resolved correction factors to account for the inlet cut-off. These corrections increase $\sigma_{\mathrm{a}, \mathrm{dry}}$ by a factor of $1.04-1.19$ in the MBL and 3.9-4.9 in the dust. No attempt has been made to correct the PSAP $\sigma_{\mathrm{a} \text {,dry }}$ to ambient $\mathrm{RH}$.

The PSAP data obtained during aircraft ascent or descent are unreliable, possibly due to the pressure variation causing bending of the filter membrane. Therefore, we only use PSAP data averaged over horizontal runs flown at several altitudes immediately before or after the vertical profiles discussed here. Adding $\sigma_{\mathrm{a}, \mathrm{dry}}$ (from PSAP) and $\sigma_{\mathrm{s} \text {,amb }}$ (from the nephelometers) will allow us to compare aerosol extinction $\sigma_{\mathrm{e}}$ with the values measured by AATS-14 or with the Caltech computational results. To extrapolate $\sigma_{\mathrm{a}, \text { dry }}(\lambda=565 \mathrm{~nm})$ to the nephelometer wavelengths we assumed $\sigma_{\mathrm{a}} \propto \lambda^{-1}$ (see Hartley et al., 2000 and references therein).

The instrumental uncertainty in $\sigma_{\mathrm{a}, \mathrm{dry}}$ is assumed to be $25 \%$ (Hartley et al., 2000). The uncertainty of the cut-off correction is assumed to be $20 \%$ and errors due to the spatial interpolation are estimated to be $<30 \%$. 
2.1.6. Auxiliary data. Temperature, pressure and dewpoint were measured by sensors outside the Pelican. After a careful end-to-end recalibration, the pressure values should be correct within $2 \mathrm{hPa}$. Unfortunately, the dewpoint sensor was not functional during ACE-2. However, knowledge of the dewpoint, or, equivalently, ambient $\mathrm{RH}$, is crucial for adjusting in-situ aerosol size distributions and nephelometer measurements to ambient conditions. Therefore, the ambient $\mathrm{RH}$ is computed as a function of ambient pressure and temperature, and, pressure, temperature and $\mathrm{RH}$ measured at the inlet of the UW-PH system assuming a constant water vapor mixing ratio. For comparison with the AATS-14 water vapor retrievals, we then computed the water vapor density as a function of ambient $\mathrm{RH}$, temperature and pressure using an expression given by Bögel (1977).

The aircraft position (i.e., geographical latitude and longitude and altitude above sea level) was determined using 2 onboard global positioning system (GPS) receivers. After the experiment, better positioning accuracy was achieved by differentially correcting the onboard GPS positions by relying on error corrections generated by a GPS receiver placed at a known station, the north airport of Tenerife. In order to have accurate time stamps for the data stream generated by each instrument the clock offsets between the Pelican payload data management system (PDMS) and the various instrument clocks were recorded during each flight. The offset between the PDMS clock and UTC was determined using the onboard GPS receivers.

\subsection{Space-borne measurements}

We use data from the Advanced Very High Resolution Radiometer (AVHRR) aboard the polar orbiting NOAA-14 spacecraft. Radiance data of the first 2 bands (channel $1-0.63 \mu \mathrm{m}$, channel $2-0.86 \mu \mathrm{m}$ center wavelengths) of the 5-channel AVHRR instrument are used in an automated process based on work developed by Brown (1997) to compute aerosol optical depth. The procedure includes a check for sun glint, a cloud screening algorithm, and a linearized singlescatter radiative transfer estimate of optical depth. Accurate estimates of optical depth from measurements of backscattered solar radiance require assumptions about the scattering phase function and single scatter albedo. In addition, estimates of the surface reflectance, water vapor and ozone absorption and molecular scattering are required. 7 model aerosol size distributions (based on Brown, 1997) were created to represent a range of variations of aerosol in the marine environment. The scattering phase functions and extinctions for these models were calculated using Mie theory. As proposed by Durkee et al. (1991) the measured aerosol radiance differences in each AVHRR pixel (channels 1 and 2) is used to choose the "best" of the 7 phase functions. For this study a nonabsorbing aerosol was assumed. A complete description of AVHRR retrieved AOD during ACE-2 is given by Durkee et al. (2000).

\subsection{Ground-based measurements}

We use a vertical AOD profile obtained from a Micro Pulse Lidar (MPL) in conjunction with a Cimel sunphotometer (Smirnov et al., 1998), both operated at the Izaña observatory $\left(28.30^{\circ} \mathrm{N}\right.$, $16.50^{\circ} \mathrm{W}, 2367 \mathrm{~m}$ ) on Tenerife. The MPL operates at a wavelength of $524 \mathrm{~nm}$. The inversion of the lidar data was constrained so that the integrated extinction profile returns the AOD (interpolated to $524 \mathrm{~nm}$ ) observed simultaneously by the Cimel sunphotometer. This assumes an altitude independent backscatter-to-extinction ratio. Details of the MPL system, its calibration, and data processing are discussed by Welton et al. (2000).

In addition, we use spectral AOD measurements at $415,501,615,675$ and $868 \mathrm{~nm}$, performed with a Multi-Filter Rotating Shadow-Band Radiometer (MFR-7, Yankee Environmental Systems, Inc., Turners Falls, MA) near the summit of "El Pico del Teide" $\left(28.27^{\circ} \mathrm{N}, 16.60^{\circ} \mathrm{W}, 3570 \mathrm{~m}\right)$ (Formenti et al., 2000).

\section{Case studies}

\subsection{Flight tf $15-8$ July 1997}

3.1.1. Situation based on satellite data, AATS-14 measurements, and back trajectories. The satellite images from NOAA-12 for 08:18 UT (Fig. 1), METEOSAT for 12:00 UT and NOAA-14 for 15:34 UT show an extensive sheet of stratocumulus clouds to the north of the Canary Islands. The flight pattern for Pelican flight tf 15, chosen to avoid cloudiness, was therefore covering the 


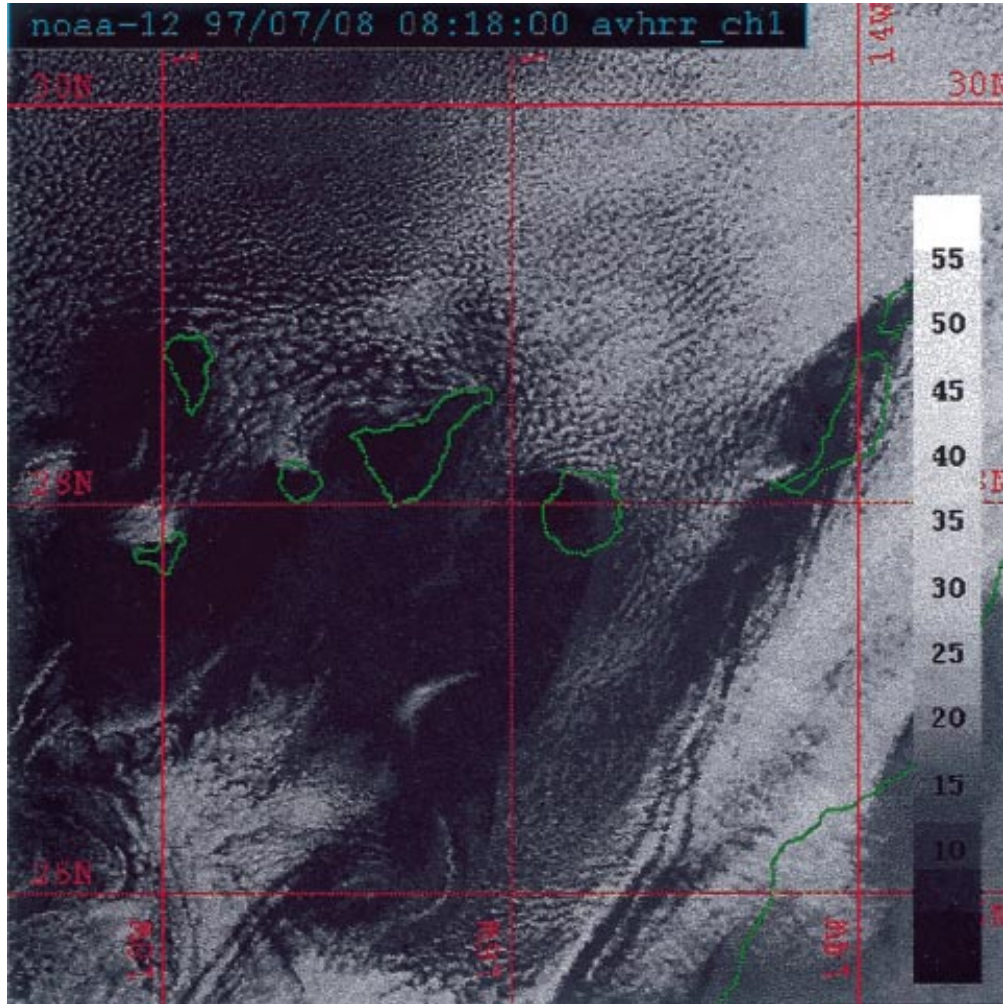

Fig. 1. NOAA-12 AVHRR channel $1(0.63 \mu \mathrm{m}$ center wavelength) image of the Canary Islands, 8 July 1997. The islands are (from left to right): Hierro, La Palma, Gomera, Tenerife, Gran Canaria, Fuerteventura, and Lanzarote. The African coastline can be seen in the lower right corner of the picture. The dimensions of the image $(x \times y)$ are $286 \times 563 \mathrm{~km}$.

mostly cloud-free region southwest of Tenerife. Here we will focus on a downward spiral flown between 10:19 and 11:03 UT close to the west coast of Gran Canaria.

The AOD and aerosol extinction profile obtained from the AATS-14 measurements is shown in Fig. 2. Below $700 \mathrm{~m}$, the direct solar beam was occasionally blocked by clouds, leading to some missing AOD values. A 3-layer structure can be observed: an MBL within which the midvisible AOD rapidly decreases from 0.3 to 0.2 , a clean layer where the total column AOD remains virtually constant up to $2.7 \mathrm{~km}$, and an implied elevated layer above $2.7 \mathrm{~km}$ where the AOD starts to decrease again. Mid-visible aerosol extinction values derived by differentiating the AOD profile are close to $0.15 \mathrm{~km}^{-1}$ near the sea surface and $0.065 \mathrm{~km}^{-1}$ in the elevated layer. A similar, although less pronounced, 3-layer structure can be seen in the $\mathrm{CWV}$ and $\mathrm{H}_{2} \mathrm{O}$ density profiles shown in Fig. 3. The MBL contains around 2/3 of the total CWV. The clean layer is rather dry, and water vapor density in the elevated layer exceeds that in the clean layer. The elevated layer extends above the Pelican's maximum flight altitude. The radio sounding taken at the north shore of Tenerife at 6:00 UT shows a temperature inversion around $5.7 \mathrm{~km}$ suggesting that the top of the elevated layer was at that altitude.

The 5-day back trajectories for this day ending at 12:00 UT on Tenerife suggest that the air in the lowest part of the MBL originated over the British Isles and Spain where it had been exposed to pollution sources. The clean air between the MBL and the elevated layer had its origin over the Atlantic to the west of Tenerife and had subsided in the free troposphere for several days. The air at the level of the elevated layer originated 

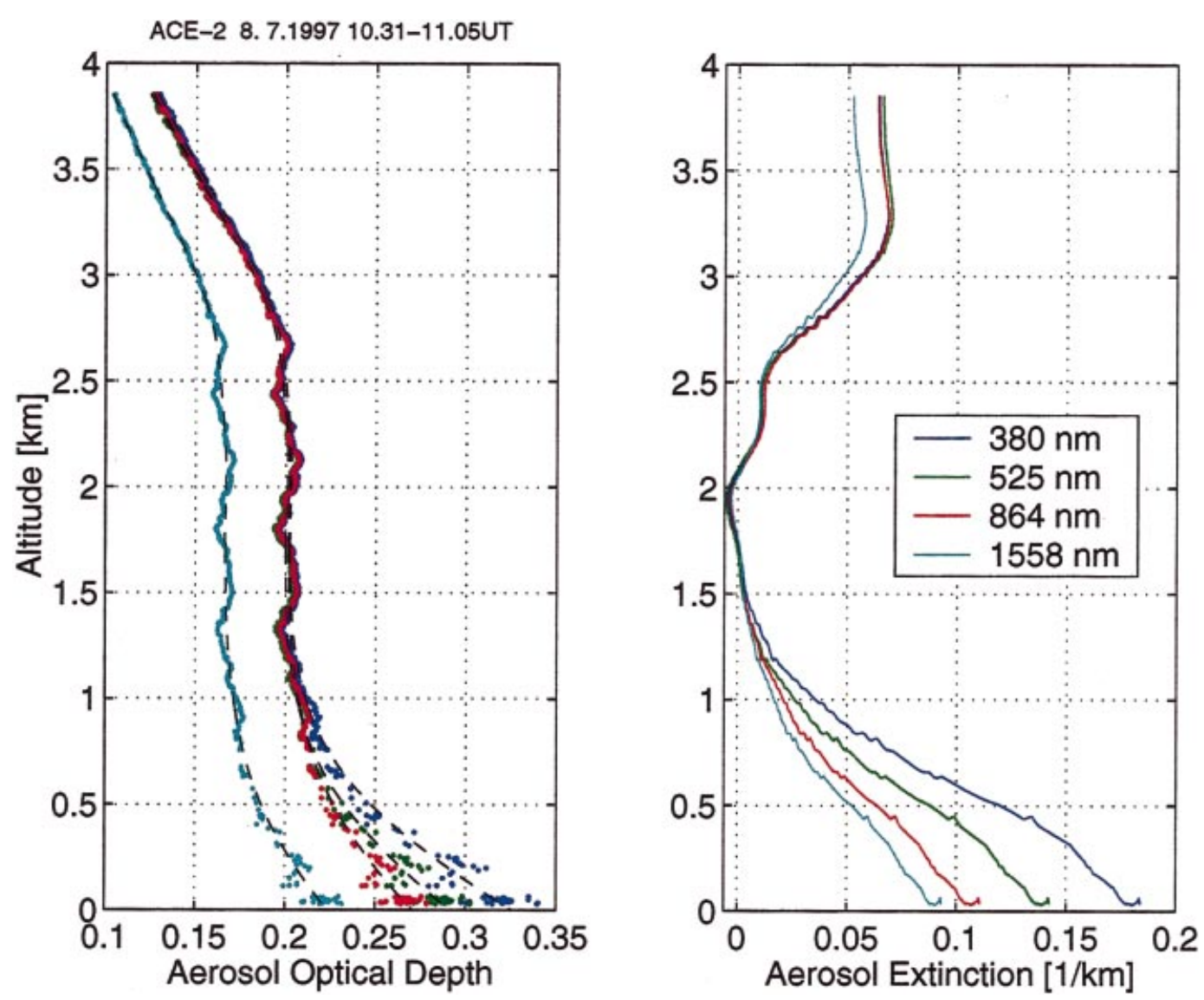

Fig. 2. Aerosol optical depth and extinction profile retrieved from AATS-14 measurements during Pelican flight tf 15 on 8 July 1997. Only 4 of 13 aerosol channels are shown. The dashed lines indicate the smoothed AOD profiles used to derive extinction.

over Africa, where it had resided for several days before arriving in Tenerife. It is considered to consist of Saharan dust. This assumption is further supported by the results of the filter analysis aboard the Pelican aircraft (Schmeling et al., 2000).

3.1.2. Water vapor comparison. In Fig. 3 , the $\mathrm{H}_{2} \mathrm{O}$ density profile obtained from the differentiated AATS-14 CWV profile is compared to the in-situ measured $\mathrm{H}_{2} \mathrm{O}$ density profile. Integrating the in-situ measured densities and adding the CWV value at the top of the profile (from AATS-14) allows comparison of the $2 \mathrm{CWV}$ profiles. With the exception of the lowest altitudes, the CWV profiles agree within the error bars of the AATS-14 retrieval alone. The $\mathrm{CVW}$ and $\mathrm{H}_{2} \mathrm{O}$ density profiles agree within $0.07 \mathrm{~g} / \mathrm{cm}^{2}$ and $1.3 \mathrm{~g} / \mathrm{m}^{3}$ (rms), respectively. The largest differences occur at the bottom of the profile.

3.1.3. Aerosol extinction and layer AOD closure. The right panel of Fig. 4 shows the aerosol extinction profiles at the green wavelength obtained from the differentiated AATS-14 AOD profile, from the in-situ measured $\sigma_{\mathrm{e}, \mathrm{amb}}$ profile (combining the $\sigma_{\mathrm{s}}$ measurements of the 3 nephelometers and the $\sigma_{\mathrm{a}}$ measurement of the PSAP instrument as described earlier) and from the Caltech computations. Integrating the in-situ measured $\sigma_{\mathrm{e}}$ values and adding the AOD value at the top of the profile (from AATS-14) allows comparison of the AOD profiles (left panel of Fig. 4). At most altitudes, the 3 AOD profiles agree within the error 

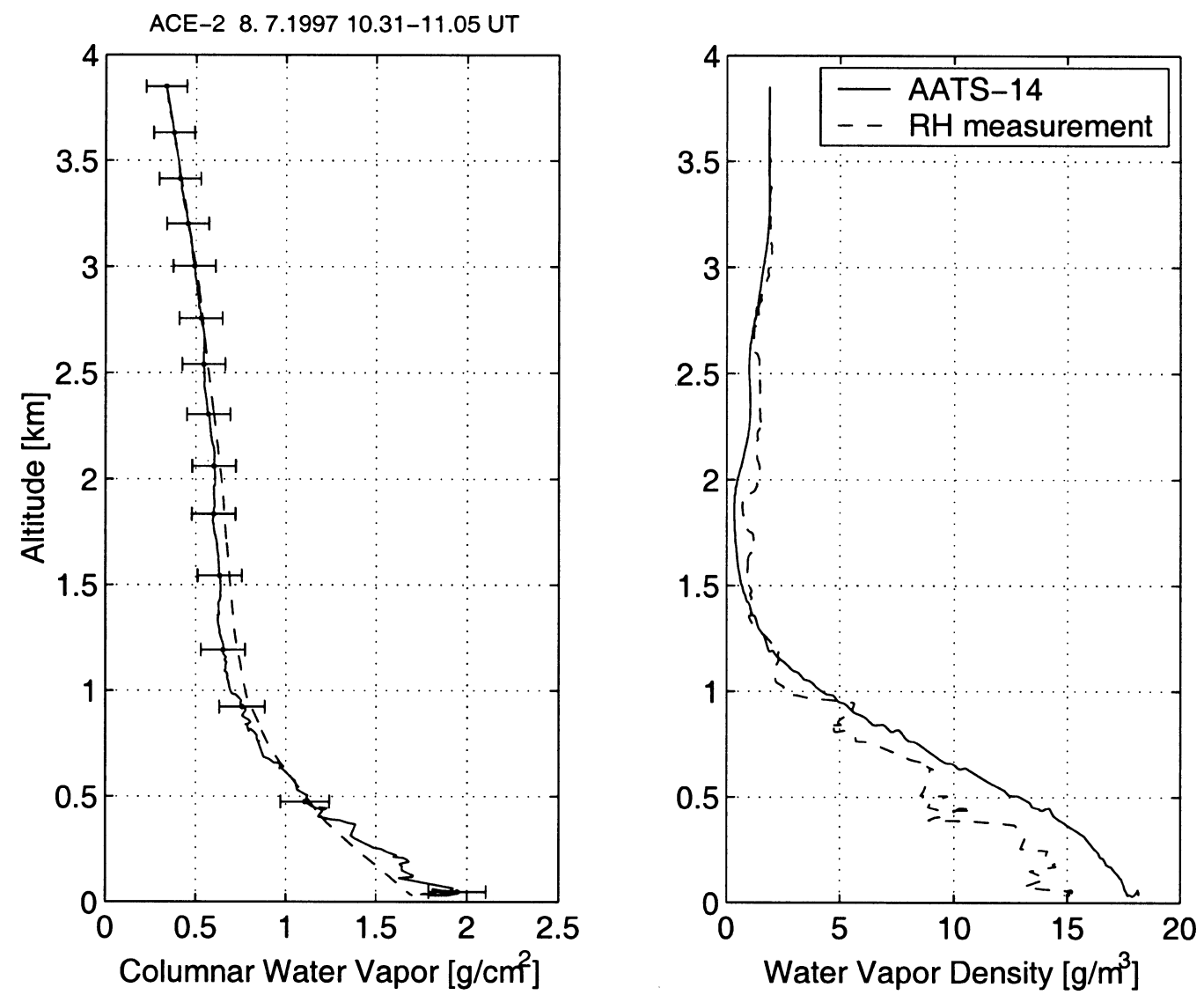

Fig. 3. Columnar water vapor and water vapor density profile retrieved from AATS-14 and UW-PH measurements during Pelican flight tf15 on 8 July 1997.

bars of the AATS-14 AOD alone. The extinction profiles agree very closely in the dust layer with somewhat larger discrepancies in the MBL. The agreement can be described more quantitatively by considering the absolute and relative differences between in-situ and AATS-14 $\sigma_{\mathrm{e}}$ profiles along with the combined (rms) error bars shown in Fig. 5. The Caltech computations agree with the AATS-14 results within the error bars of both techniques, with the exception of 3 points near the top of the MBL. In the dust layer, the Caltech and AATS-14 $\sigma_{\mathrm{e}}$ values agree within $0.005 \mathrm{~km}^{-1}$ (rms). In the MBL the agreement is $0.017 \mathrm{~km}^{-1}$ The results from nephelometer/PSAP and AATS-14 agree within error bars in the dust layer, but in the MBL the differences are larger than the error bars. In the dust layer the nephelometer/PSAP and AATS-14 $\sigma_{\mathrm{e}}$ values agree within $0.006 \mathrm{~km}^{-1}$ (rms). In the MBL the $\mathrm{rms}$ difference is $0.028 \mathrm{~km}^{-1}$.

Next, we focus on layer AODs caused by the dust and the MBL aerosols, but this time we consider the full spectral information available. For AATS-14, layer AODs are obtained by subtracting the AOD at the top of the considered layer from the AOD at the bottom of the layer. The in-situ results are integrated vertically through the same layer. For the MBL (Fig. 6), the largest layer AODs are obtained from the AATS-14 measurements. The Caltech layer spectra is steeper: the AODs are lower by $0.002(2 \%)$ at $380 \mathrm{~nm}, 0.008$ $(10 \%)$ at $525 \mathrm{~nm}$, and $0.02(40 \%)$ at $1558 \mathrm{~nm}$. The nephelometer/PSAP spectrum is even steeper than the Caltech spectrum. The AODs differ from the AATS-14 results by $0.018(20 \%)$ at $450 \mathrm{~nm}, 0.022$ $(28 \%)$ at $530 \mathrm{~nm}$ and $0.028(44 \%)$ at $700 \mathrm{~nm}$. 

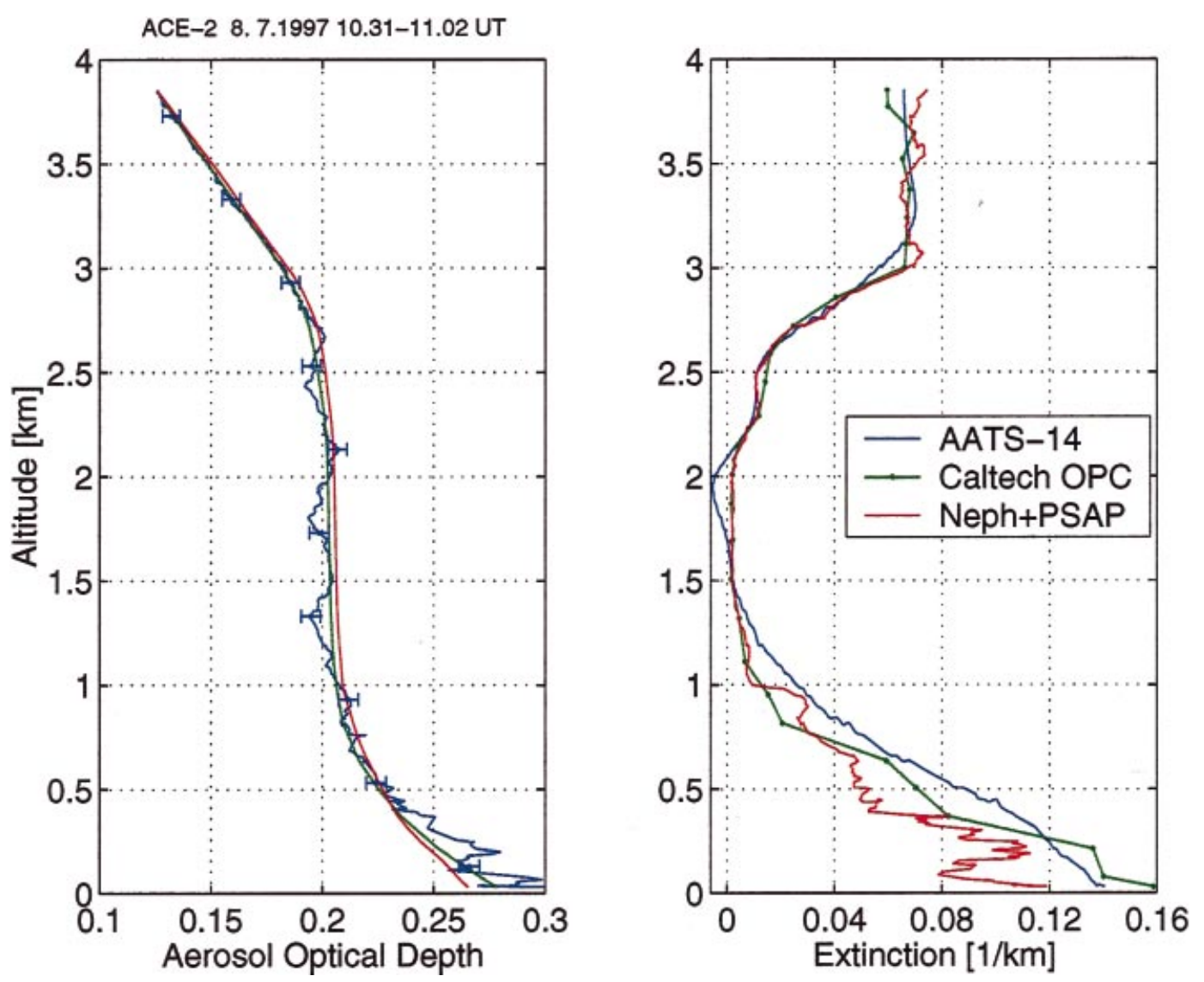

Fig. 4. Aerosol optical depth and extinction profile retrieved from AATS-14 $(\lambda=525 \mathrm{~nm})$, from size distribution measurements (Caltech OPC, $\lambda=525 \mathrm{~nm}$ ), and by combining scattering and absorption measurements of 3 nephelometers and the PSAP instrument during Pelican flight tf 15 on 8 July 1997.

These differences are larger than the combined error bars. For the dust (Fig. 7), the layer AODs of Caltech and AATS-14 agree almost perfectly at all wavelengths (3-8\%) except at $1558 \mathrm{~nm}(23 \%)$. The nephelometer/PSAP layer AOD spectrum is again steeper but at all wavelengths, the differences $(3-19 \%)$ are within error bars.

\subsection{Flight tf $20-17$ July 1997}

3.2.1. Situation based on satellite data, AATS-14 measurements, and back trajectories. For this day also, the satellite image (Fig. 8) from NOAA-14 (15:36 UT) shows an extensive sheet of stratocumulus clouds to the north of the Canary Islands. The sky was mostly clear to the south of the islands with some island-induced wake clouds.
The flight pattern for Pelican flight tf20, again chosen to avoid cloudiness, is shown in Fig. 9. The entire flight lasted from 14 to 20 UT. Here we will focus on the down spiral and the horizontal runs south of Tenerife, and on the down and up spirals above the Izaña observatory on Tenerife.

The AOD and aerosol extinction profiles obtained from the AATS-14 measurements during the down spiral are shown in Fig. 10. Again, a 3-layer structure can be observed: an MBL within which the total column (mid-visible) AOD decreases from 0.37 to 0.32 , a clean layer between 1 and $2 \mathrm{~km}$ altitude where the total column AOD remains virtually constant, and an elevated layer where the AOD decreases from 0.3 to 0.06 . The elevated layer must have extended somewhat above the Pelican's maximum flight altitude, 

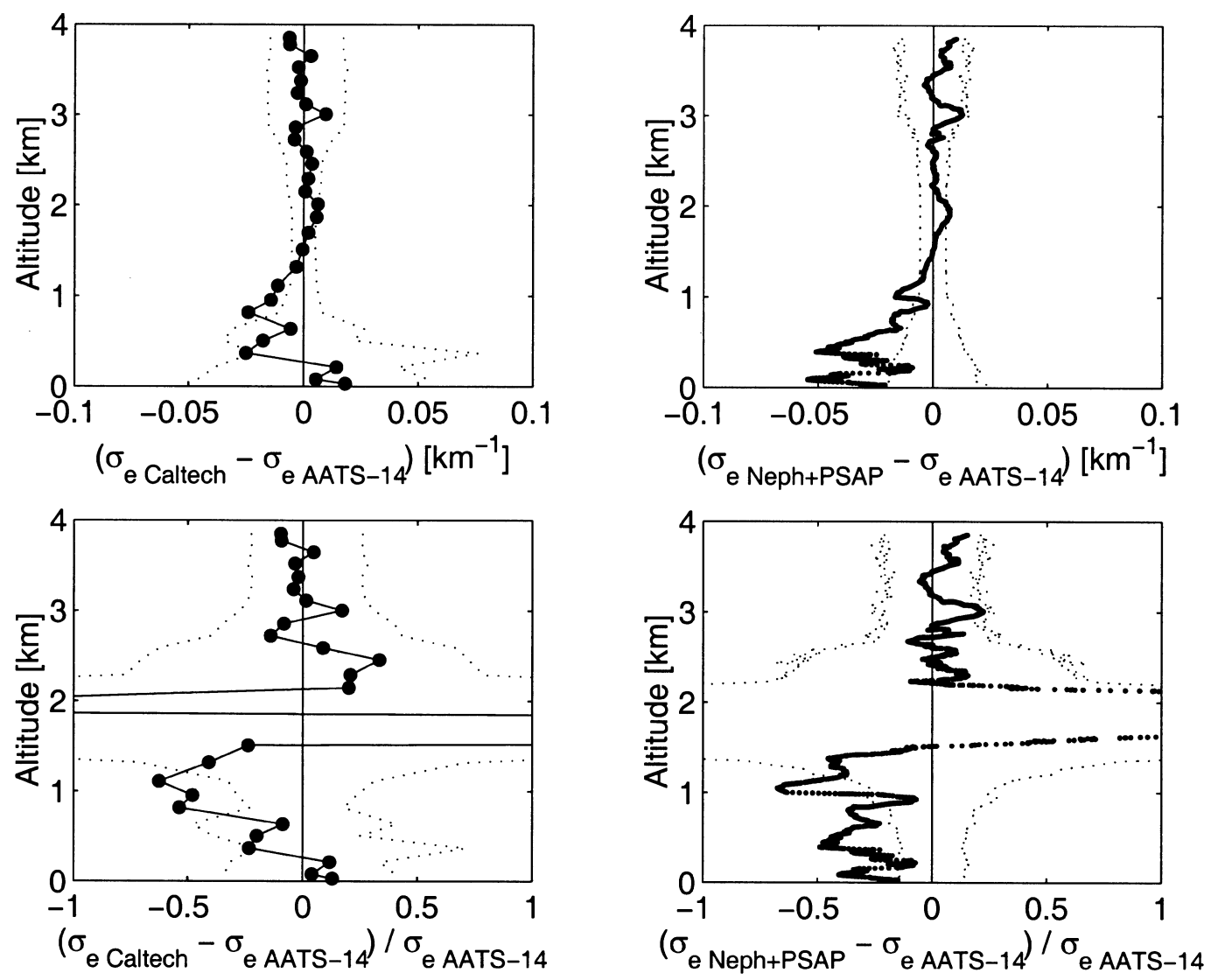

Fig. 5. Absolute (top) and relative differences (bottom) of aerosol extinction at the green wavelength from Caltech computations (left), from nephelometers and PSAP (right), relative to AATS-14 for the profiles shown in Fig. 4. The dashed lines depict the combined errors of the compared results.

because during ACE-2 the AOD at maximum Pelican flight altitude was well below 0.01 on clean days. Indeed the lidar operated at Izaña showed the top of the dust layer to be near $5 \mathrm{~km}$ throughout the whole day. The mid-visible aerosol extinction values derived by differentiating the AATS-14 AOD profile are close to $0.1 \mathrm{~km}^{-1}$ near the sea surface and $0.17 \mathrm{~km}^{-1}$ in the elevated layer. The $\mathrm{CWV}$ and $\mathrm{H}_{2} \mathrm{O}$ density profiles are shown in Fig. 11. The MBL contains around 60\% of the total CWV. Again, the clean layer is rather dry, whereas the elevated layer shows enhanced water vapor densities.

The 5-day back trajectories ending at 12:00 UT on Tenerife indicate a marine source for the air in the lowest part of the MBL. The trajectory suggests that the air remained in the MBL during all
5 days prior to arriving at Tenerife. The clean air between the MBL and the elevated layer originated over the Iberian Peninsula. The air at the level of the elevated layer had its origin over Africa south of Tenerife. It is considered to consist of Saharan dust, which is in accord with the filter measurements of Schmeling et al. (2000).

Neglecting the free-tropospheric plus stratospheric background (AOD $<0.01$, see above), we observe that on 17 July the dust layer has an AOD of $0.3(\lambda=500 \mathrm{~nm})$ versus 0.2 on 8 July, and the dust extinction is larger by a factor of 2.6. However, the extinction in the MBL is smaller on 17 July than on 8 July probably because of the different origin of these airmasses. Nevertheless, the AOD values obtained on 17 July at sea level (the bottom of the spiral shown in Fig. 10) are the 


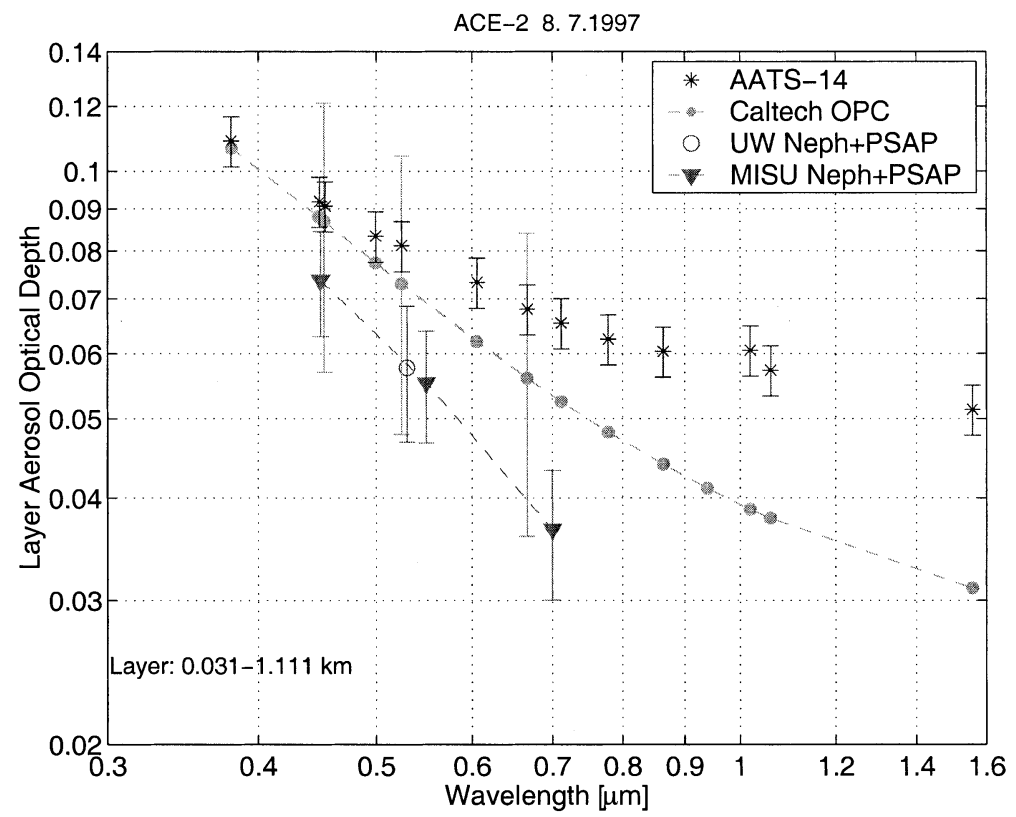

Fig. 6. Spectral aerosol optical depth for the MBL (31-1111 m) during Pelican flight tf 15 on 8 July 1997.

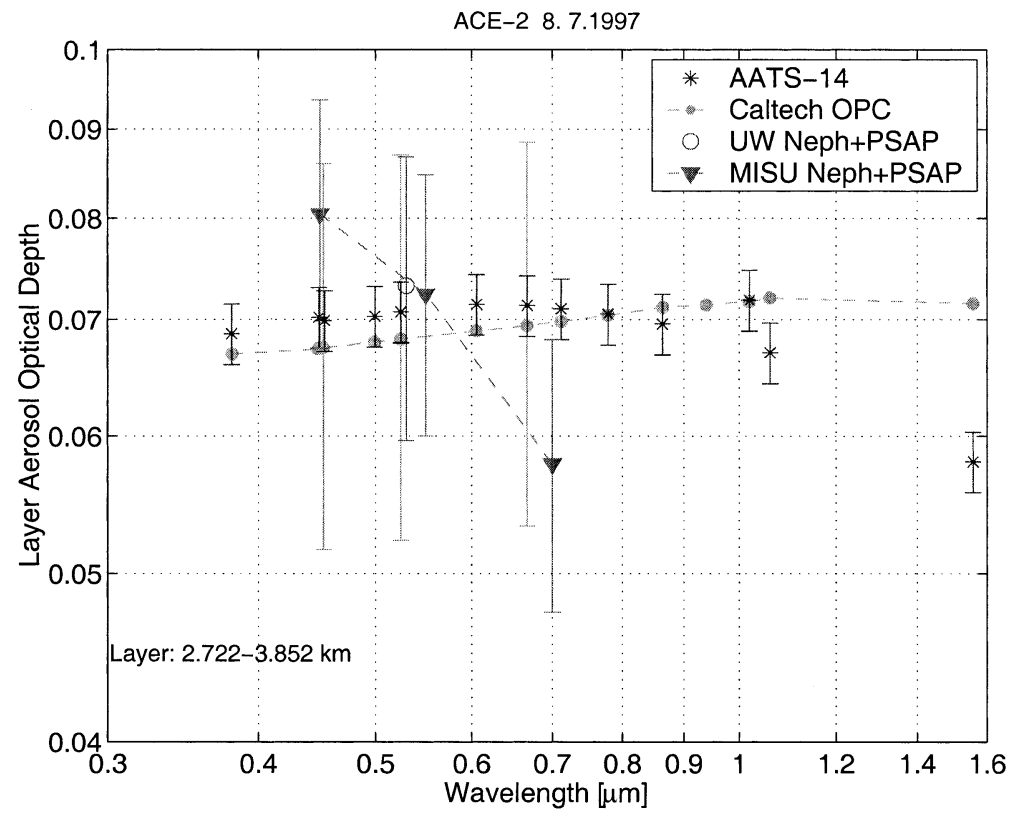

Fig. 7. Spectral aerosol optical depth for part of the dust layer (2722-3852 m) during Pelican flight tf 15 on 8 July 1997. 


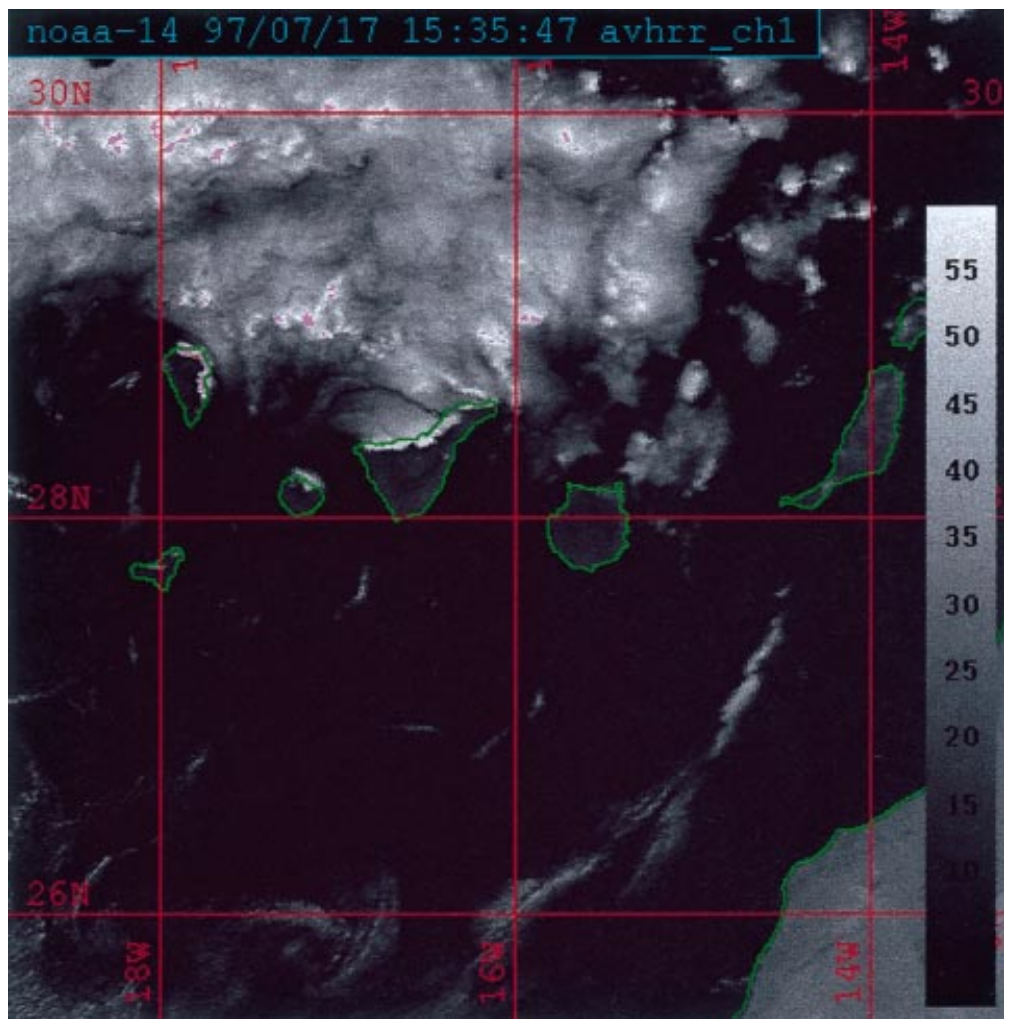

Fig. 8. Same as Fig. 1 but for NOAA-14 on 17 July 1997.

largest values measured by AATS-14 throughout the entire ACE-2 campaign.

3.2.2. Water vapor comparison. In Fig. 11, the $\mathrm{H}_{2} \mathrm{O}$ density profile obtained from the differentiated AATS-14 CWV profile is compared to the in-situ measured $\mathrm{H}_{2} \mathrm{O}$ density profile. The agreement is $1.7 \mathrm{~g} / \mathrm{cm}^{3}$ (rms), with some larger differences occurring in the $250-600 \mathrm{~m}$ altitude range. With the exception of the lowest altitudes, the 2 CWV profiles agree within the error bars of the AATS-14 retrieval alone. The rms difference is $0.09 \mathrm{~g} / \mathrm{cm}^{2}$.

3.2.3. Aerosol extinction and layer AOD closure. Fig. 12 shows the aerosol extinction and AOD profiles obtained using the 3 different methods (nephelometers/PSAP, Caltech computations and AATS-14). For this case, the disagreement is larger than for the 8 July case discussed before. The extinction profiles from Caltech and AATS-14 are still fairly close. The nephelometer/PSAP results are considerably lower in the dust. The absolute and relative differences along with the combined error bars are shown in Fig. 13. With the exception of a few points, the Caltech computations agree with the AATS-14 results throughout the entire profile within the error bars of both techniques. The agreement between nephelometer/PSAP and AATS-14 is outside the error bars in the dust layer, but within error bars for most of the MBL. The rms differences in the MBL are $0.017 \mathrm{~km}^{-1}$ (Caltech) and $0.016 \mathrm{~km}^{-1}$ (nephelometer/PSAP). In the dust, the rms differences between in-situ and AATS-14 $\sigma_{\mathrm{e}}$ values are considerably larger than for the 8 July case: $\sim 0.04 \mathrm{~km}^{-1}$ (rms). This is caused by the especially large difference at the top of the profile. The largest relative differences between in-situ and AATS- $14 \sigma_{\mathrm{e}}$ occur at the boundaries of the 3 layers, and at the top of the profile. This is probably a result of the smoothing of the AATS-14 AOD profiles prior to differentiation, and shows the limitations of retrieving extinction profiles from airborne sunphotometer measurements. 

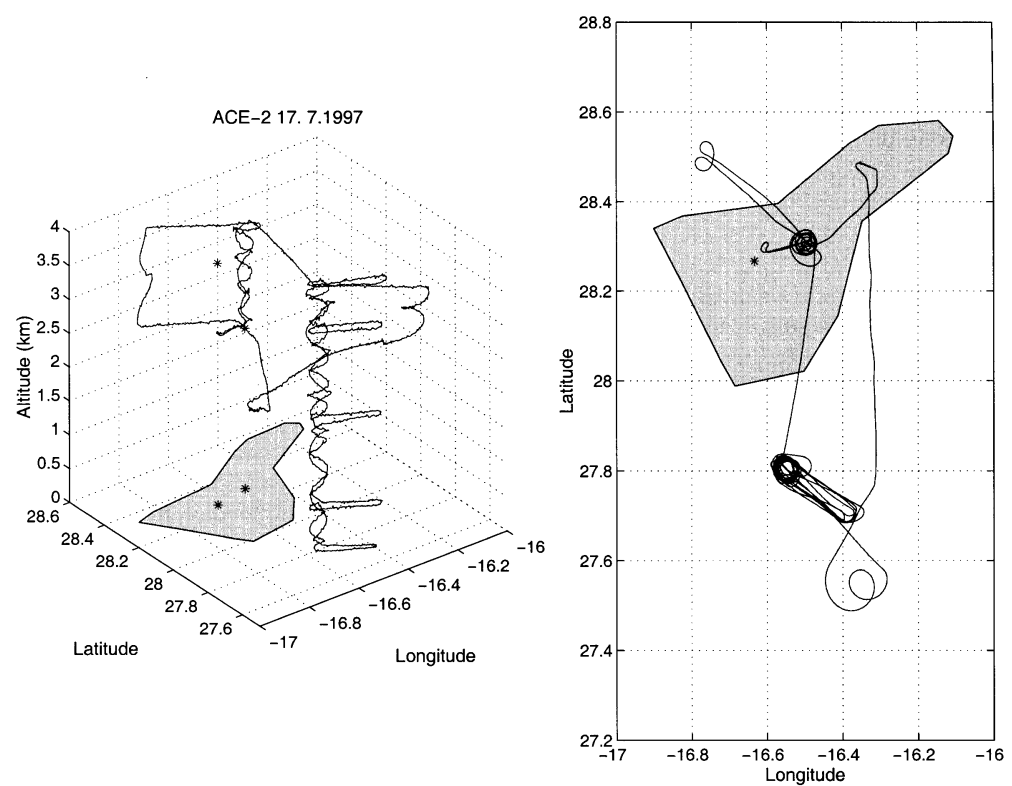

Fig. 9. Flight pattern for Pelican flight tf 20 on 17 July 1997. The asterisks denote the geographical location and altitude of the observation sites at the Izaña observatory and near the summit of "El Pico del Teide".

The layer AOD comparisons shown in Figs. 14,15 do not require such smoothing. In the MBL (Fig. 14), the layer AODs obtained with the 3 techniques agree within the combined error bars. This time the slopes of Caltech and the AATS-14 spectra are similar, whereas the nephelometer/PSAP spectrum is again slightly steeper. Compared to AATS-14, the Caltech AODs are lower by $15 \%$ at $380 \mathrm{~nm}, 17 \%$ at $525 \mathrm{~nm}$ and $27 \%$ at $1558 \mathrm{~nm}$. The nephelometer/PSAP AODs are lower by $13 \%$ at $450 \mathrm{~nm}, 16 \%$ at $530 \mathrm{~nm}$ and $23 \%$ at $700 \mathrm{~nm}$. In the dust (Fig. 15), the layer AODs of Caltech and AATS-14 agree almost perfectly at all wavelengths $(2-5 \%)$ except at $1558 \mathrm{~nm}(18 \%)$. The nephelometer/PSAP AODs are lower by $20 \%$ at $450 \mathrm{~nm}, 26 \%$ at $530 \mathrm{~nm}$ and $38 \%$ at $700 \mathrm{~nm}$. Only the result at the shortest nephelometer wavelength agrees within the error bars. The nephelometer/PSAP layer AOD spectrum is again steeper.

Part of the observed difference in spectral slope between nephelometer/PSAP and AATS-14 results might stem from our use of a wavelength independent value of $\gamma$ in (2). In theory $\gamma$ should be increasing with increasing wavelength, because particle growth will cause $\sigma_{\mathrm{s}}(\lambda)$ to increase more at longer wavelengths. Experimental evidence for such an increase was found by Kotchenruther et al. (1999) and Carrico et al. (2000). Also our assumption of $\sigma_{\mathrm{a}} \propto \lambda^{-1}$ can lead to an error in the spectral slope.

The consistent discrepancy between the AATS-14 and the Caltech dust spectra at $1558 \mathrm{~nm}$ (Figs. 7, 15) might be caused by assuming that the real part of the refractive index, $m=n^{\prime}-n^{\prime \prime} i$, of the dust aerosol is $n^{\prime}=1.56$ independent of wavelength. Indeed the Patterson et al. (1977) measurements taken on "El Pico del Teide" on Tenerife indicate that $n^{\prime}=1.575$ at $440 \mathrm{~nm}$ and $n^{\prime}=1.55$ at $650 \mathrm{~nm}$. For a Sahara dust sample taken at Barbados, Volz (1973) obtained $n^{\prime}=1.5$ at $500 \mathrm{~nm}$ and $n^{\prime}=1.45$ at $2500 \mathrm{~nm}$. Furthermore, the spectral behavior of Sahara dust extinction as computed by d'Almeida (1987) from measured size distributions using wavelength-dependent values of $n^{\prime}$ (by combining the $n^{\prime}$ values from Patterson et al. (1977) and Volz (1973)) is very similar to the spectral behavior of the AATS-14 layer AODs shown in Figs. 7, 15.

3.2.4. Aerosol size-distribution closure. Instead of computing $\sigma_{\mathrm{e}}$ from the in-situ size-distribution data and comparing this with the extinction or AOD obtained from AATS-14, we may compare size distributions by inverting the AATS-14 extinction spectra. For that purpose, the Caltech and 

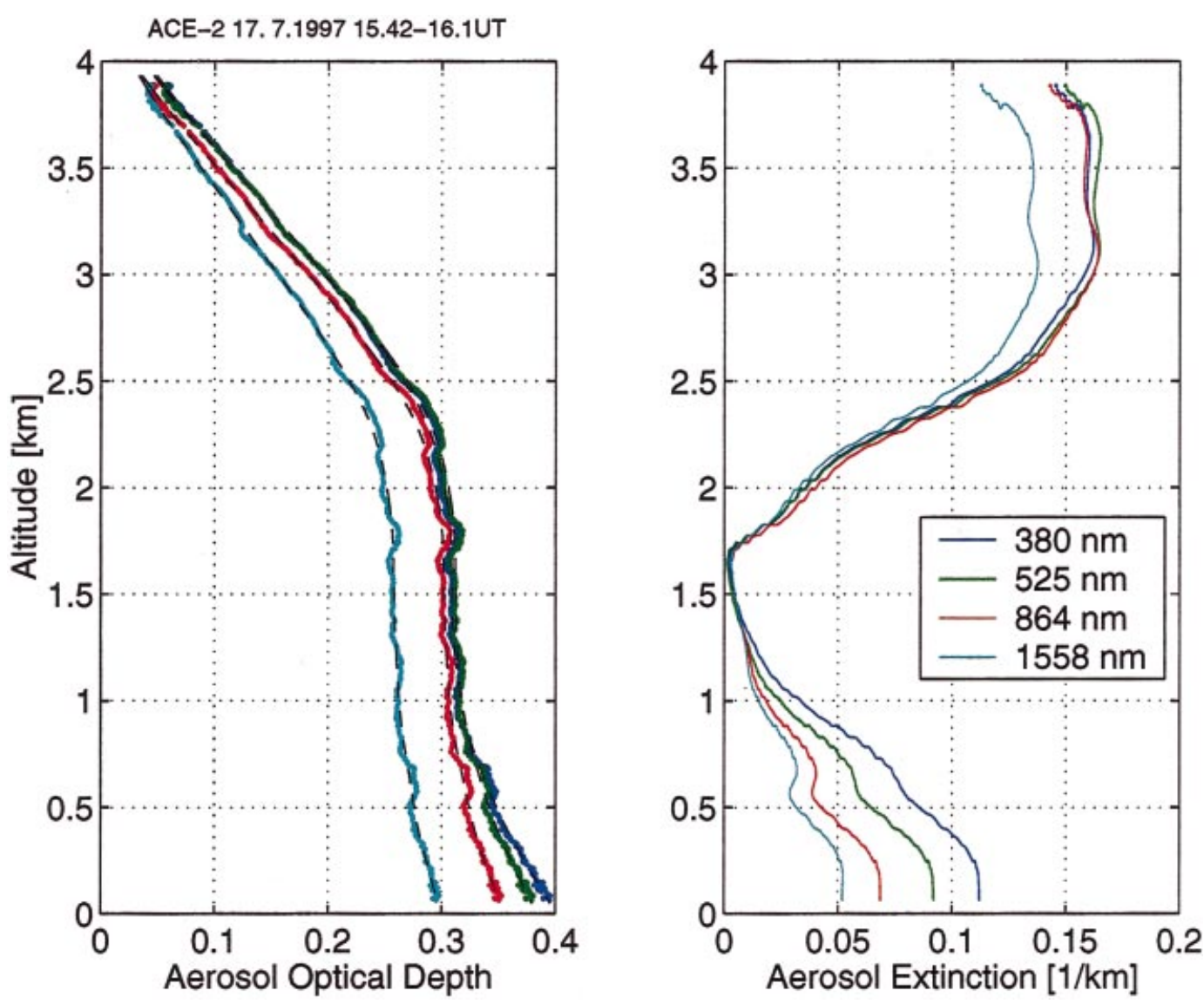

Fig. 10. Aerosol optical depth and extinction profile retrieved from AATS-14 measurements during Pelican flight tf 20 on 17 July 1997. Only 4 of 13 aerosol channels are shown. The dashed lines indicate the smoothed AOD profiles used to derive extinction.

the AATS-14 extinction values are averaged over identical 8-min intervals. In Figs. 16, 17, we show the area size distributions retrieved in the MBL and the dust. Table 1 compares the integrated quantities such as number, $N$, surface area, $S$, volume, $V$, and effective radius, $R_{\text {eff }}$.

In the MBL (Fig. 16) a wavelength-independent refractive index of $m=1.4-0.0035 i$ (Tanré et al., 1997) has been used in the inversion of the AATS-14 data. The agreement is within error bars for $2 / 3$ of the size bins. As shown in Table $1, S, V$, and $R_{\text {eff }}$ agree almost perfectly. The AATS-14 size distributions cover only the size range where the aerosol particles are optically active. Therefore, we cannot expect the particle number concentration, $N$, to agree. It should be mentioned that the unusually large value of $N=6565 \mathrm{~cm}^{-3}$ (Table 1) measured by Caltech in the MBL is caused by an island aerosol plume.

In the dust layer (Fig. 17) the area size distributions look very similar in shape and magnitude, but the distributions peak at different diameters. The differences between the distributions exceed the error bars except where the curves cross. Of the integrated quantities (Table 1 ) only $S$ agrees within error bars. We attribute the lack of agreement to the assumption of a nondispersive aerosol $(m=1.55-0.005 i)$ in the inversion of the AATS-14 extinction spectrum (see discussion in Subsection 3.2.3).

3.2.5. AOD column closure. Fig. 18 shows the AOD $(\lambda=0.63 \mu \mathrm{m})$ retrieved from AVHRR radi- 

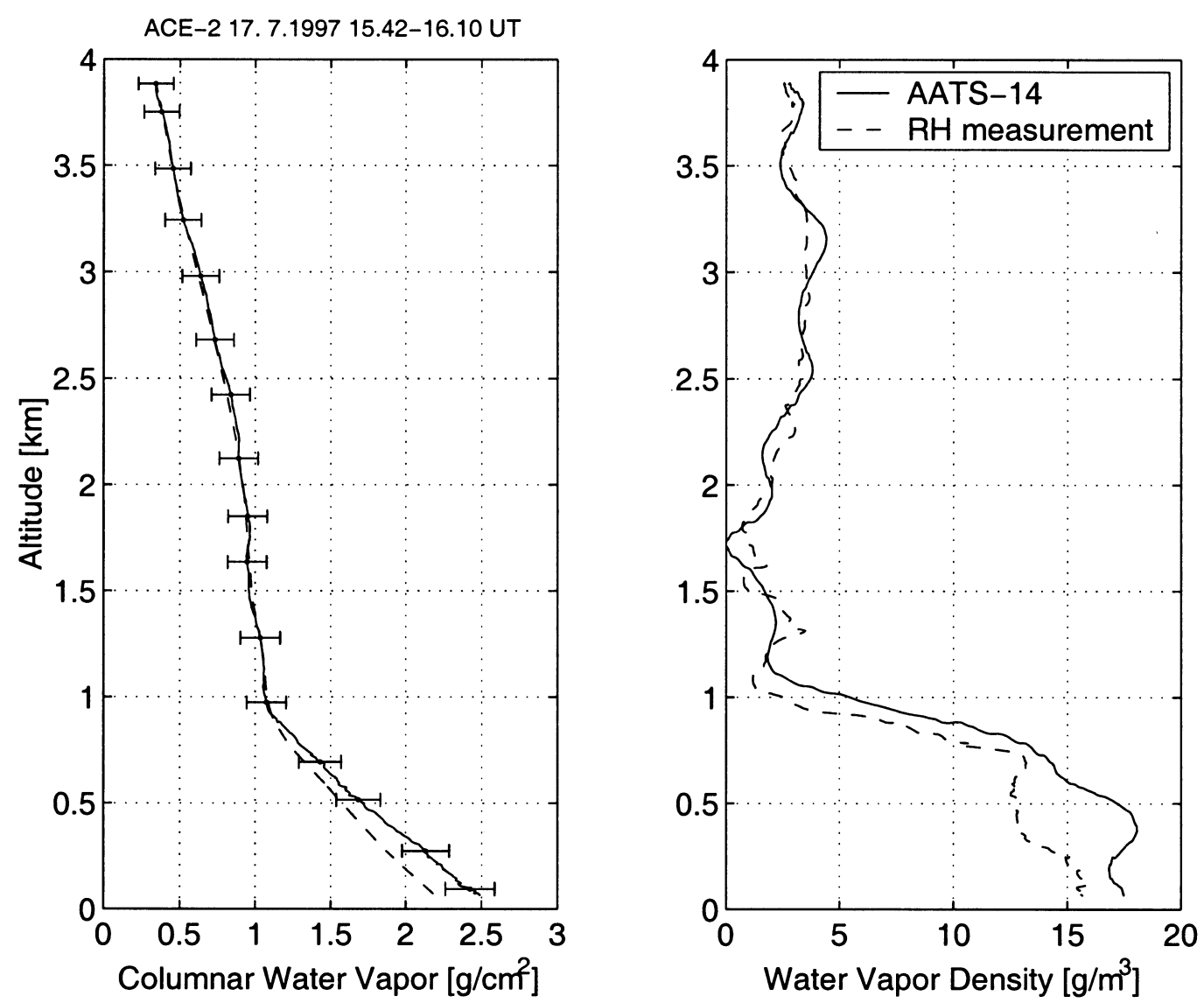

Fig. 11. Columnar water vapor and water vapor density profile retrieved from AATS-14 and UW-PH measurements during Pelican flight tf 20 on 17 July 1997.

ances. In order to identify areas where the AOD retrieval is contaminated by clouds, Fig. 18 can be compared with Fig. 8. Enhanced AODs up to 0.5 can be observed along the African coast extending into the Canary Islands. A strong gradient from areas with dust to areas without dust can be observed north of the islands. During Pelican flight tf 20 , an oval-shaped horizontal run was flown close to the ocean surface within the box depicted in Fig. 18 (see also Fig. 9). The low flight altitude (20-35 m) allows a comparison of the total column AOD as retrieved by AATS-14 and AVHRR. The results shown in Fig. 19 represent the most common AVHRR AODs within the box ( 15 by 15 pixels) and the mean AATS-14 AODs along the Pelican run. The narrow error bars represent the retrieval errors; the wide error bars are maximum and minimum AODs within the box or along the Pelican run. At the shorter AVHRR wavelength, the AODs agree within 0.03, that is within the wide error bars of both methods. At the longer wavelength the difference is as large as 0.08 , larger than the error bars. This is in accord with the results of Durkee et al. (2000), where the generally good agreement between AVHRR and sunphotometer retrieved AOD (see also Livingston et al., 2000) is reduced by the presence of dust, especially at the longer AVHRR wavelength. This might be caused by the fact that the AVHRR retrieval is currently assuming a nonabsorbing aerosol, with phase functions for marine aerosols.

3.2.6. AOD intercomparisons. During flight tf 20, the Pelican flew a down and an up spiral along 

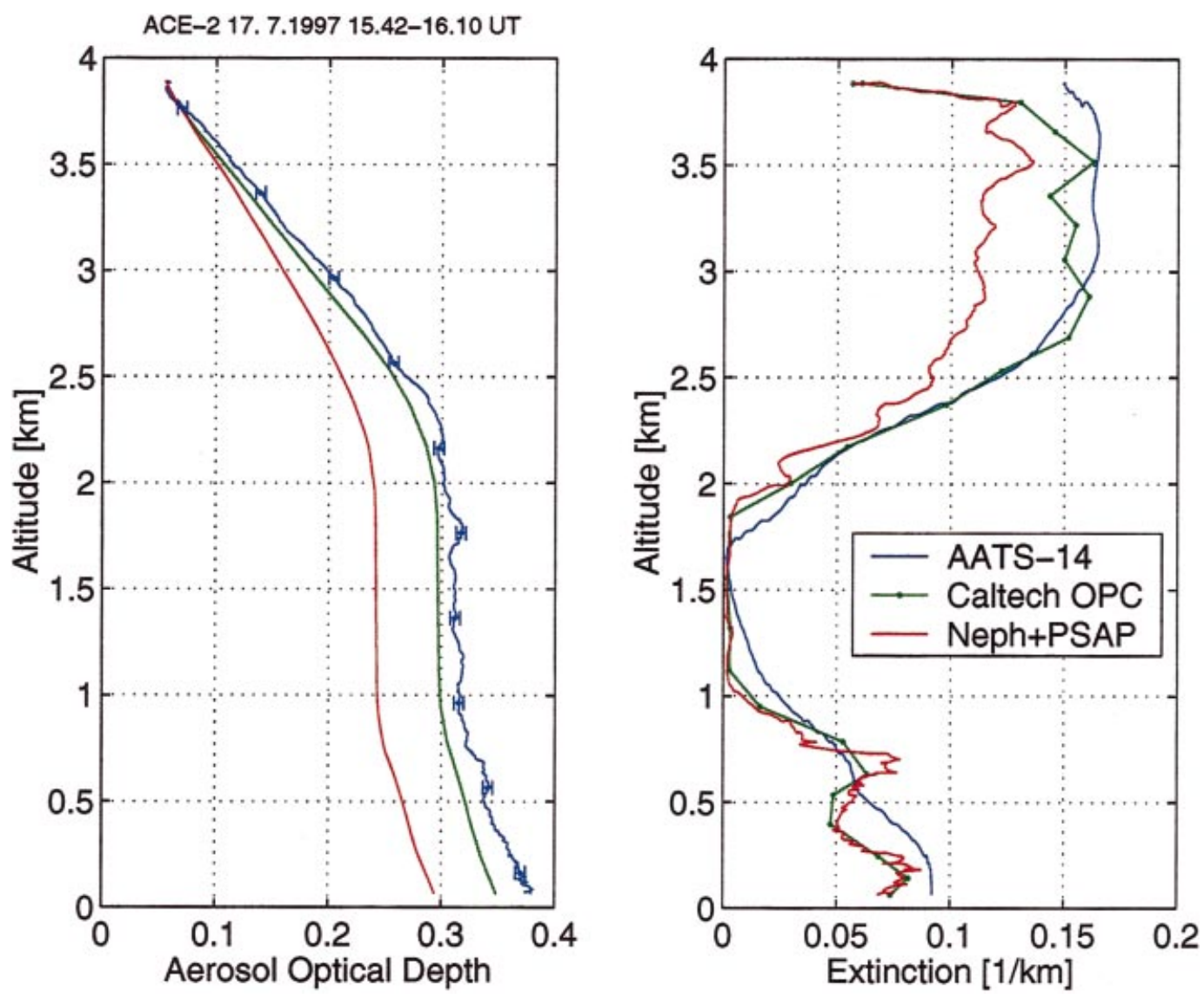

Fig. 12. Same as Fig. 4 but for Pelican flight tf 20 on 17 July 1997.

the vertical path of the Micro Pulse Lidar (MPL) operated simultaneously at the Izaña observatory on Tenerife. The AOD profile obtained by vertically integrating the lidar extinction $(\lambda=524 \mathrm{~nm})$ and the AODs $(\lambda=524.8 \mathrm{~nm})$ obtained by AATS-14 are shown in Fig. 20. Also plotted in Fig. 20 are the AOD value of the Cimel sunphotometer at the location of the MPL and the AOD value measured by the MFR at nearby Teide at $3570 \mathrm{~m}$ a.s.l. (for both instruments the AODs are interpolated to $\lambda=524 \mathrm{~nm}$ ). The agreement among all instruments is well within 0.02 , and for most of the profile the MPL and the AATS-14 agree within 0.01 or better.

The full AATS-14 AOD spectrum can be compared to the simultaneous spectral AOD from the MFR on Teide, when the Pelican reaches the corresponding altitude. The 2 AOD spectra
(Fig. 21) agree within 0.005. This level of agreement is remarkable, considering that the AOD results are obtained by 2 independent systems, using a different measurement approach and independent data reduction algorithms.

\section{Summary and conclusions}

Based on CLEARCOLUMN studies performed on 8 and 17 July 1997 the following conclusions can be drawn:

On both days columnar water vapor and water vapor density profiles from 0 to $4 \mathrm{~km}$ derived from in-situ RH measurements and solar transmission measurements in the $0.94 \mu \mathrm{m}$ band agree within $10 \%$ and $30 \%$ (rms), respectively.

On both days closure was achieved for $\sigma_{\mathrm{e}}$ 

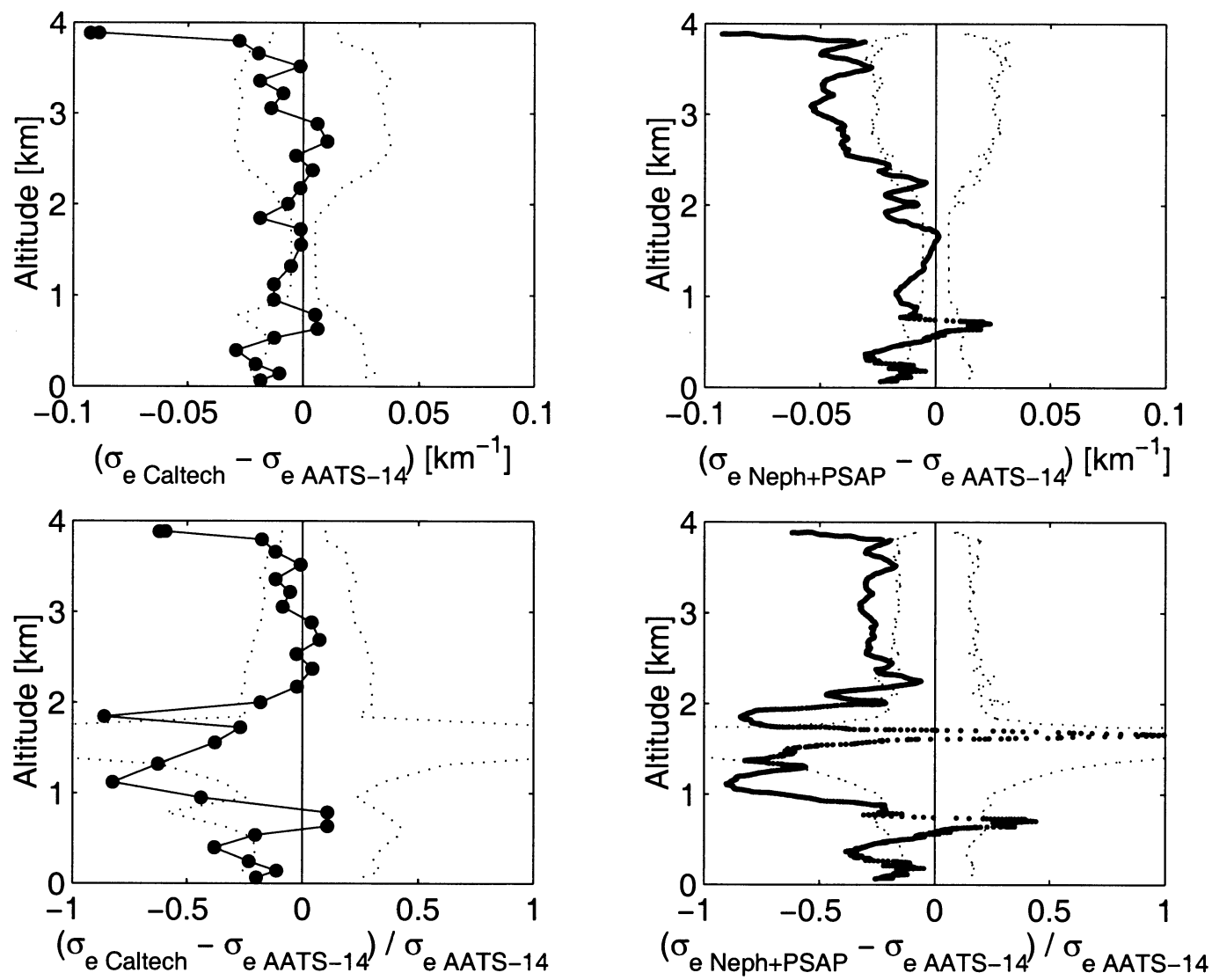

Fig. 13. Same as Fig. 5 but for the profiles shown in Fig. 12.

$(\lambda=525 \mathrm{~nm})$ profiles $(0-4 \mathrm{~km})$ computed from in-situ size-distributions and AATS-14 measurements within the $0.006-0.05 \mathrm{~km}^{-1}$ error bars of the measurements and the models.

Layer AOD $(\lambda=380-1060 \mathrm{~nm})$ closure based on in-situ size-distributions and AATS-14 measurements was achieved on both days in the MBL and the elevated dust layer. In the dust the agreement is almost perfect 3-8\% (8 July) and 2-5\% (17 July). On both days the Caltech computations overpredict the measured dust layer AOD at $\lambda=$ $1558 \mathrm{~nm}$, by $\sim 20 \%$. We attribute this to the fact that the real part of the refractive index, $n^{\prime}$, was held constant in the Caltech computations, whereas in reality it might decreases with increasing wavelength (Patterson et al., 1977; Volz, 1973). However, we are not aware of any measurements of $n^{\prime}$ that cover the entire spectral range (380 to
$1558 \mathrm{~nm}$ ) used here. In the MBL, there is a tendency for the Caltech computations to be slightly lower than the AATS-14 measurements. The best agreement is achieved at the shortest wavelength $(380 \mathrm{~nm}) 2 \%$ on 8 July and $15 \%$ on 17 July whereas at $1558 \mathrm{~nm}$, the Caltech results are lower by $40 \%$ ( 8 July) and $27 \%$ ( 17 July). These spectral differences might again be caused by assuming a wavelength independent refractive index in the Caltech computations. However, at the wavelengths where an error analysis of the Caltech $\sigma_{\mathrm{e}}$ was performed, the differences are within the error bars $(40 \%)$ of the Caltech computations alone.

Aerosol size-distribution closure based on in-situ size distributions and inverted AATS-14 extinction spectra has been achieved in the MBL. $S, V$, and $R_{\text {eff }}$ agree within $0.2,7$ and $7 \%$, respectively. In the dust layer, size-distribution closure 


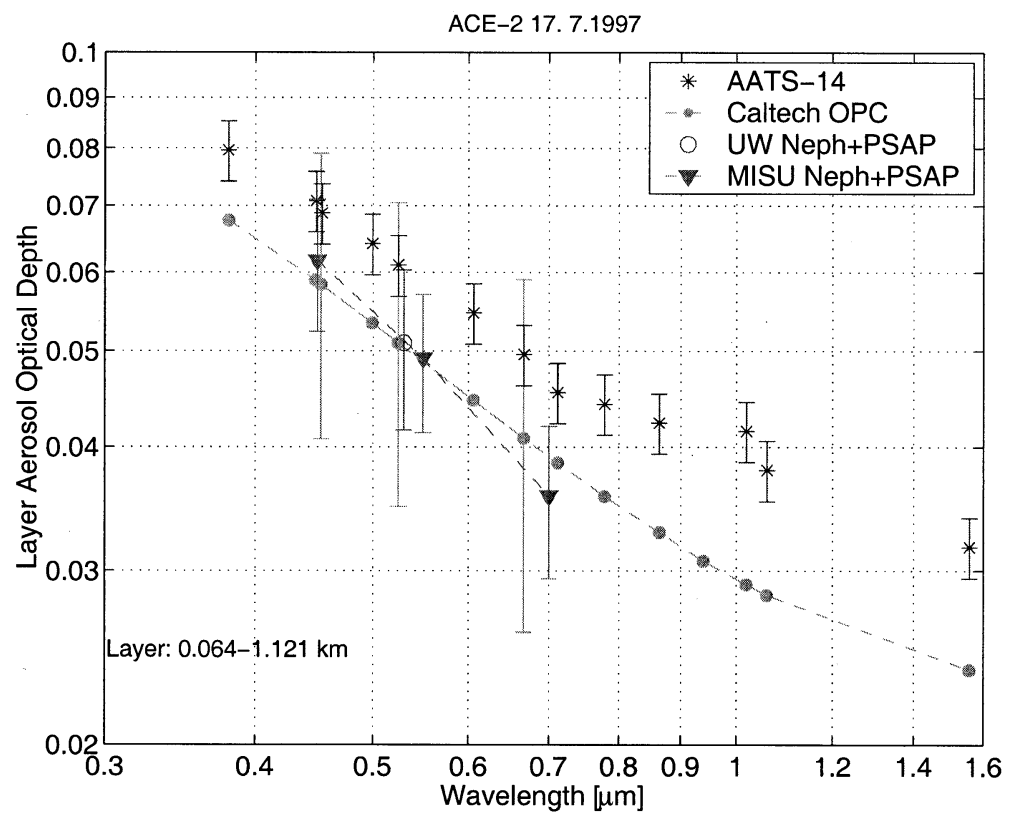

Fig. 14. Spectral aerosol optical depth for the MBL (64-1121 m) during Pelican flight tf20 on 17 July 1997.

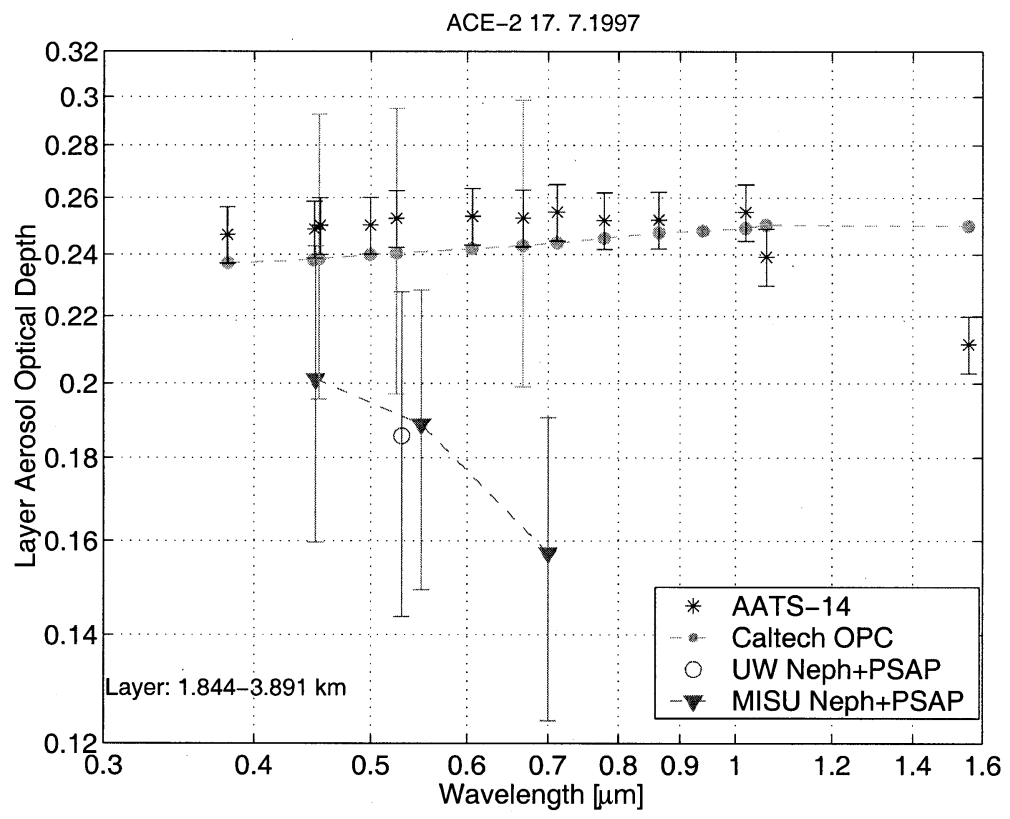

Fig. 15. Spectral aerosol optical depth for part of the dust layer (1844-3891 m) during Pelican flight tf 20 on 17 July 1997. 


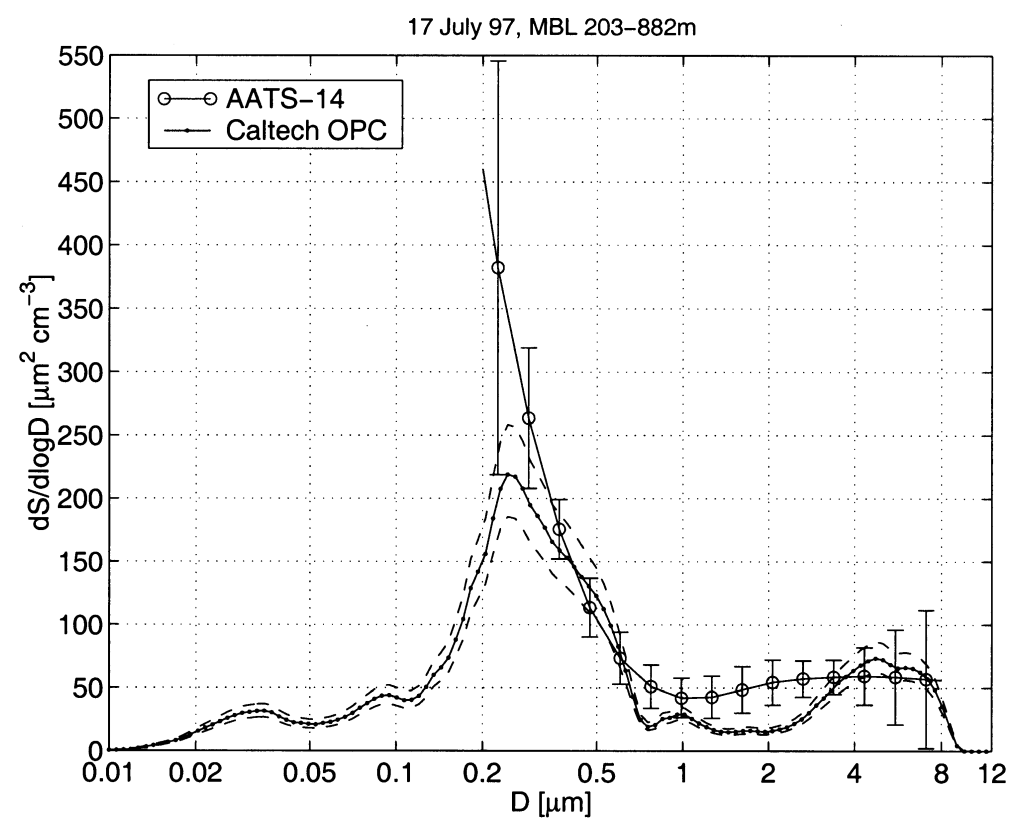

Fig. 16. Comparison of MBL area size distributions from in-situ measurements and from inverted AATS-14 spectral extinction measurements during Pelican flight tf20 on 17 July 1997. Dashed lines indicate uncertainties of the Caltech results.

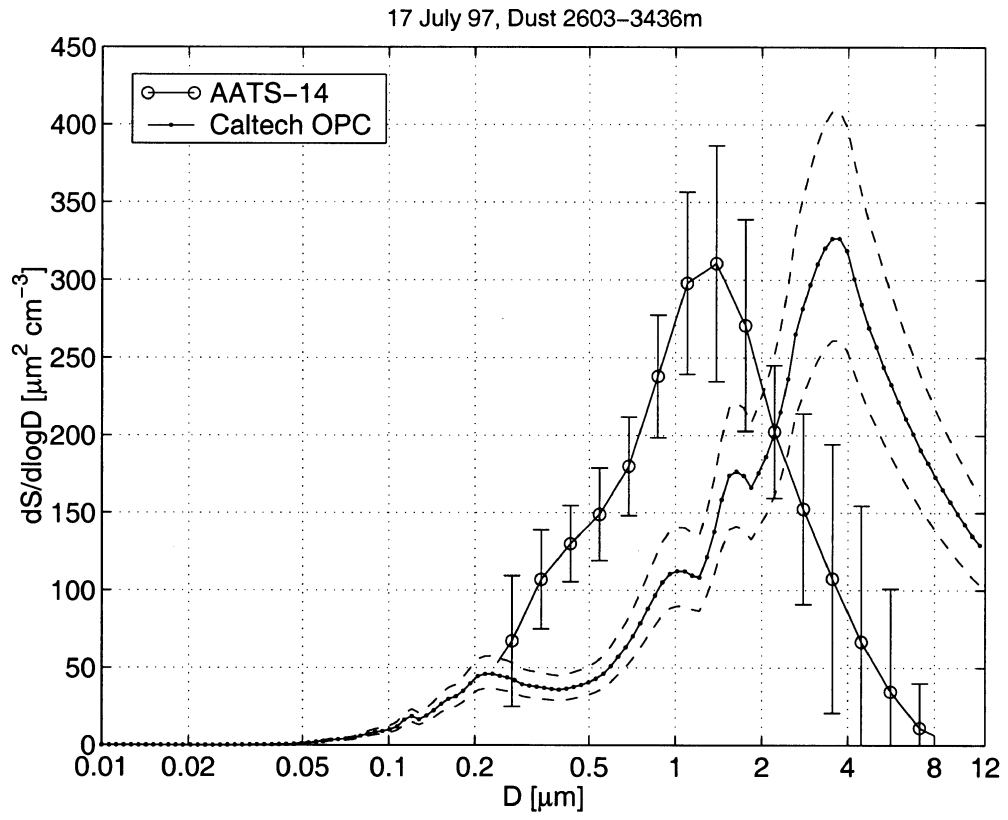

Fig. 17. Same as Fig. 16 but for elevated dust layer. 
Table 1. Quantities from integrated size distributions during Pelican flight tf20 on 17 July 1997

\begin{tabular}{|c|c|c|c|c|c|c|c|c|c|c|c|}
\hline \multirow{2}{*}{$\begin{array}{l}\text { Instrument } \\
\text { Caltech }\end{array}$} & \multicolumn{2}{|c|}{$\begin{array}{l}\text { Time } \\
\text { (UT) }\end{array}$} & \multicolumn{2}{|c|}{$\begin{array}{l}\text { Altitude } \\
\quad(\mathrm{m})\end{array}$} & \multirow{2}{*}{$\begin{array}{l}\text { Type } \\
\text { Dust }\end{array}$} & \multirow{2}{*}{$\begin{array}{c}\begin{array}{c}\text { Number } \\
\left(1 / \mathrm{cm}^{3}\right)\end{array} \\
291\end{array}$} & \multirow{2}{*}{$\begin{array}{c}\begin{array}{c}\text { Area } \\
\left(\mu \mathrm{m}^{2} / \mathrm{cm}^{3}\right)\end{array} \\
267\end{array}$} & \multirow{2}{*}{$\begin{array}{c}\begin{array}{c}\text { Volume } \\
\left(\mu \mathrm{m}^{3} / \mathrm{cm}^{3}\right)\end{array} \\
159\end{array}$} & \multirow{2}{*}{$\begin{array}{c}\begin{array}{c}\text { Density } \\
\left(\mathrm{g} / \mathrm{cm}^{3}\right)\end{array} \\
2.65\end{array}$} & \multirow{2}{*}{$\begin{array}{c}\begin{array}{c}\text { Mass } \\
\left(\mu \mathrm{g} / \mathrm{m}^{3}\right)\end{array} \\
422\end{array}$} & \multirow{2}{*}{$\begin{array}{r}\begin{array}{c}R_{\text {eff }} \\
(\mu \mathrm{m})\end{array} \\
1.79\end{array}$} \\
\hline & $15: 31$ & $15: 39$ & 3436 & 2603 & & & & & & & \\
\hline AATS-14 & $15: 31$ & $15: 39$ & 3436 & 2603 & Dust & 139 & 234 & 60 & 2.65 & 159 & 0.77 \\
\hline Difference & & & & & & $110 \%$ & $14 \%$ & $166 \%$ & & $166 \%$ & $133 \%$ \\
\hline Unc. Caltech & & & & & & $23 \%$ & $25 \%$ & $27 \%$ & & $27 \%$ & $5 \%$ \\
\hline Unc. AATS-14 & & & & & & $32 \%$ & $33 \%$ & $51 \%$ & & $51 \%$ & $18 \%$ \\
\hline Caltech & $15: 55$ & $16: 03$ & 882 & 203 & MBL & 6565 & 166 & 32.8 & 1.30 & 42.7 & 0.60 \\
\hline AATS-14 & $15: 55$ & $16: 03$ & 882 & 203 & MBL & 450 & 165 & 35.4 & 1.30 & 46.0 & 0.64 \\
\hline Difference & & & & & & $1360 \%$ & $0.2 \%$ & $-7 \%$ & & $-7 \%$ & $-7 \%$ \\
\hline Unc. Caltech & & & & & & $15 \%$ & $18 \%$ & $21 \%$ & & $21 \%$ & $5 \%$ \\
\hline Unc. AATS-14 & & & & & & $31 \%$ & $33 \%$ & $50 \%$ & & $50 \%$ & $19 \%$ \\
\hline
\end{tabular}

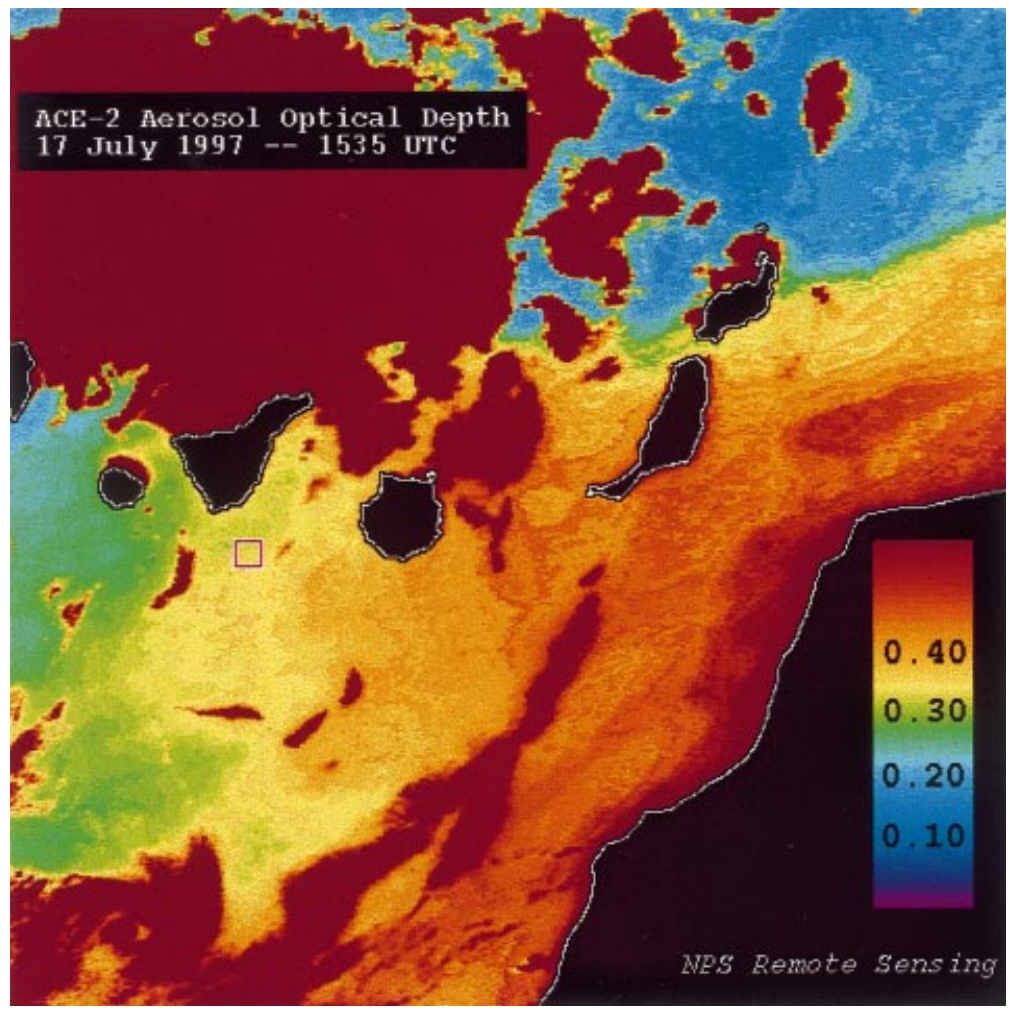

Fig. 18. AOD $(\lambda=0.63 \mu \mathrm{m})$ retrieved from AVHRR radiances. Compare with Fig. 8 to localize areas of cloud contamination.

could not be achieved. We believe that this is due to our use of a wavelength-independent refractive index in the inversion of the AATS-14 spectra. If both the discrepancy at $1558 \mathrm{~nm}$ and the lack of closure can be resolved by using a wavelength- dependent dust refractive index remains to be investigated.

Extinction closure $(\lambda=525 \mathrm{~nm})$ between nephelometer/PSAP and AATS-14 was achieved on 8 July for altitudes above $1.1 \mathrm{~km}$ within the 


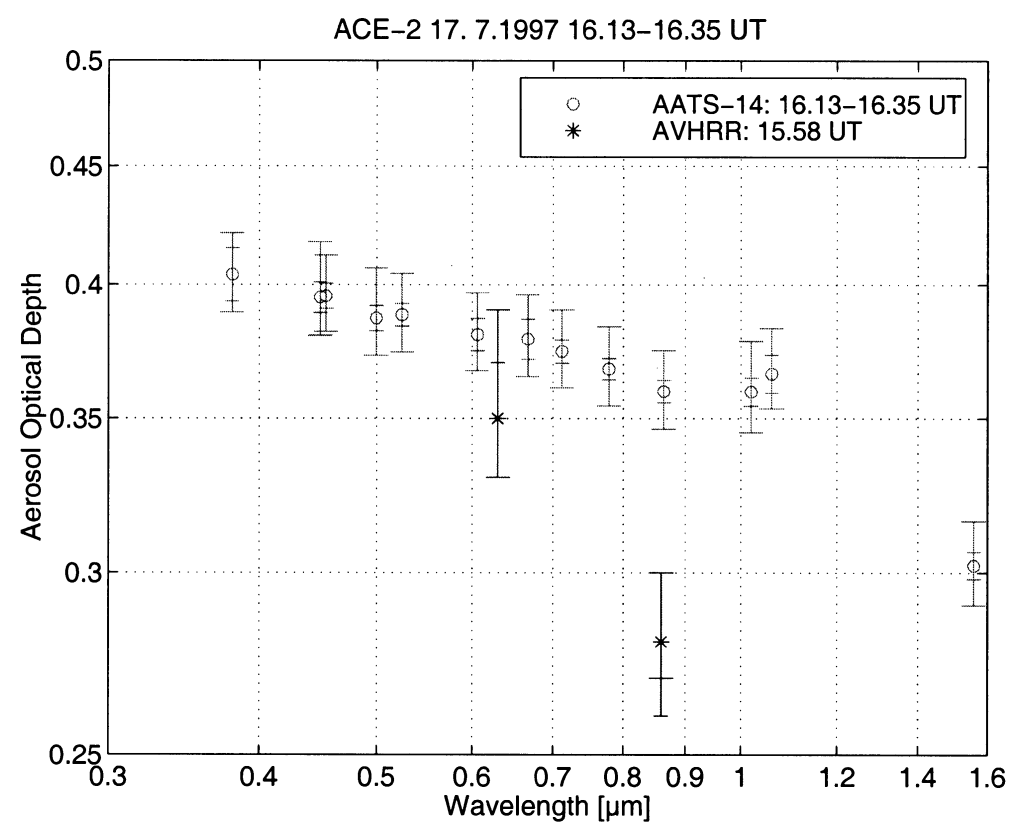

Fig. 19. Comparison of AOD as retrieved by AVHRR and AATS-14. For explanations of error bars see text.

$0.007-0.03 \mathrm{~km}^{-1}$ error bars of the measurements and the models. On 17 July, closure could not be achieved for most of the profile.

Layer AOD $(\lambda=450-700 \mathrm{~nm})$ closure between nephelometer/PSAP and AATS-14 in the dust layer was achieved on 8 July $(\triangle \mathrm{AOD}:+15$ to $-19 \%$ ) but not on 17 July ( $\triangle$ AOD: -19 to $-38 \%$ ). In the MBL, closure was achieved on 17 July ( $\triangle$ AOD: -13 to $-23 \%$ ) but not on 8 July ( $\triangle$ AOD: -20 to $-44 \%$ ). The fact that the nephelometers and the PSAP sampled the aerosol through a cyclone makes those measurements less useful for the closure study carried out here. Large corrections (especially in the dust) had to be applied. Therefore, it is not surprising that closure with AATS-14 was not always achieved.

The agreement of the sea level AOD as retrieved from AVHRR radiances and measured by AATS-14 suffered from the presence of the elevated dust layer due to the assumptions (i.e., non-absorbing aerosol, phase functions) made in the AVHRR retrieval algorithm (Durkee et al., 2000). In the absence of such dust layers, AVHRR and AATS-14 values typically agree within error bars (Durkee et al., 2000; Livingston et al., 2000).

Comparing vertical AOD profiles obtained by
AATS-14 and a ground-based lidar leads to agreement well within 0.02 at all altitudes (better than 0.01 at most altitudes). Comparing a groundbased sunphotometer (MFR) AOD spectrum taken on Teide $(3570 \mathrm{~m})$ with an AATS-14 airborne AOD spectrum at the same altitude leads to agreement within 0.005 .

The aerosol extinction and layer AOD closure achieved in the dust between the Caltech computations (based on continuous size-distribution measurements) and AATS-14 (based on continuous airborne AOD measurement) is noteworthy because several previous attempts to do this were not successful (Carlson and Caverly, 1977; Fouquart et al., 1987; Clarke et al., 1996). The extinction and layer AOD closure in the MBL accomplished in this study has been achieved previously by Clarke et al. (1996) during the 1992 Atlantic Stratocumulus Transition Experiment (ASTEX).

Various layer AOD closure studies based on airborne nephelometer/PSAP and airborne or ground-based sunphotometer measurements have been performed in the past (Remer et al., 1997; Hegg et al., 1999; Hartley et al., 2000; Kato et al., 2000, to be issued). A comparison of the aerosol optical 


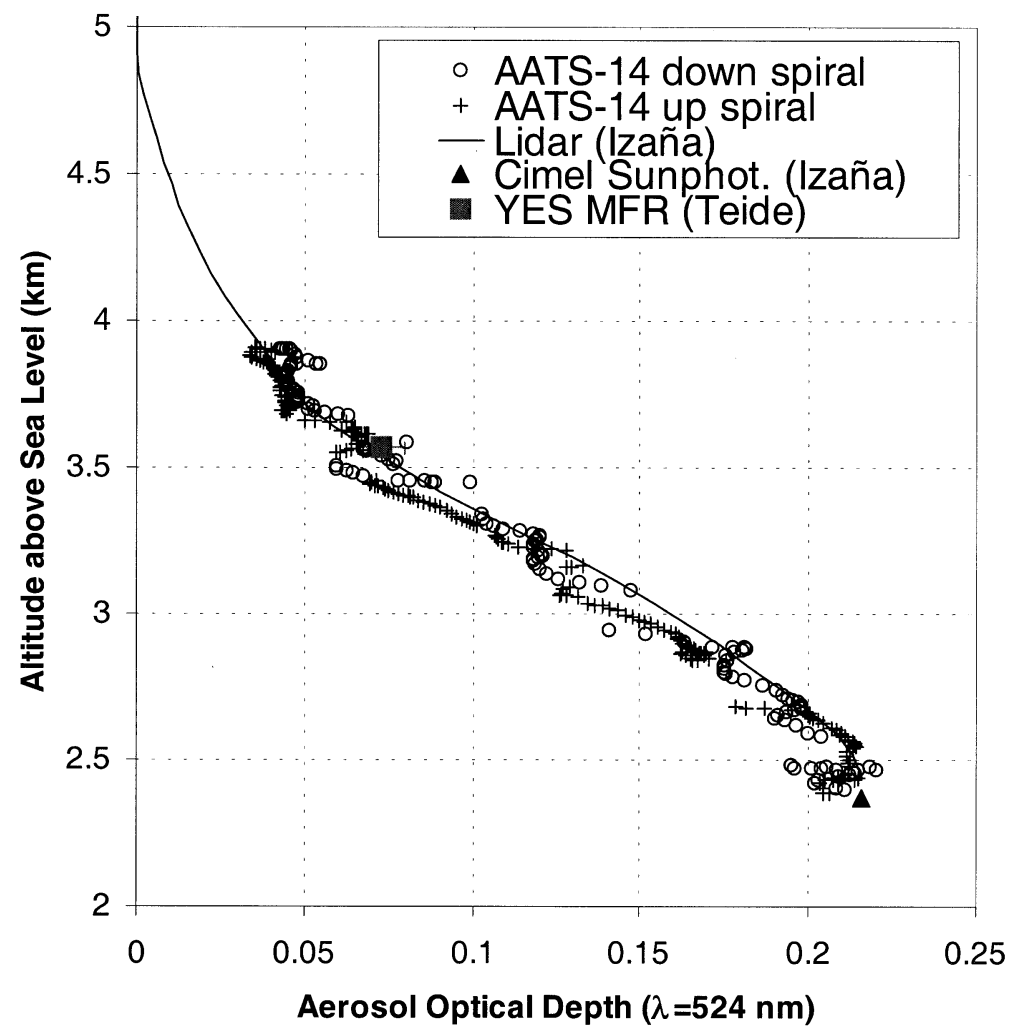

Fig. 20. AOD profiles from lidar $(\lambda=524 \mathrm{~nm})$ and AATS-14 $(\lambda=524.8 \mathrm{~nm})$ above Izaña. The lidar profile is constrained to match the Cimel AOD. Also shown the MFR AOD at nearby Teide at $3570 \mathrm{~m}$ a.s.l. (for Cimel and MFR the AODs are interpolated to $\lambda=524 \mathrm{~nm}$ ).

thickness derived from ground-based and airborne measurements, submitted to Journal of Geophysical Research, 1999). Closure (in-situ results lower by $12 \pm 5 \%$, at $450 \mathrm{~nm}$ ) was achieved by Hegg et al. (1999), and Hartley et al. (2000) based on the same data set covering $12 \mathrm{MBL}$ cases obtained during TARFOX.

It is noteworthy, that extinction or layer AOD closure between in-situ and sunphotometer measurements has been achieved only in those studies (Clarke et al., 1996; Hegg et al., 1999; Hartley et al., 2000; Collins et al., 2000, and this study) where both measurements were taken from the same airplane. Also it is remarkable that in all the closure studies mentioned above the in-situ measurements yield $\sigma_{\mathrm{e}}$ or layer AODs that are almost always lower than those obtained with sunphotometer measurements. Possible reasons for these differences are at this point speculative, but there are some phenomena reported in the literature that might provide at least partial explanations. These phenomena include (1) possible loss of semivolatile aerosol material during direct sampling (Eatough et al., 1996), and (2) gas absorption that may be present but is not accounted for in sunphotometer analyses (Halthore et al., 1998).

\section{Acknowledgements}

This research was conducted as part of the second Aerosol Characterization Experiment (ACE-2), which is a contribution to the International Global Atmospheric Chemistry (IGAC) core project of the International Geosphere-Biosphere Programme (IGBP). Financial support for the measurements and analyses was provided by the US National Science 


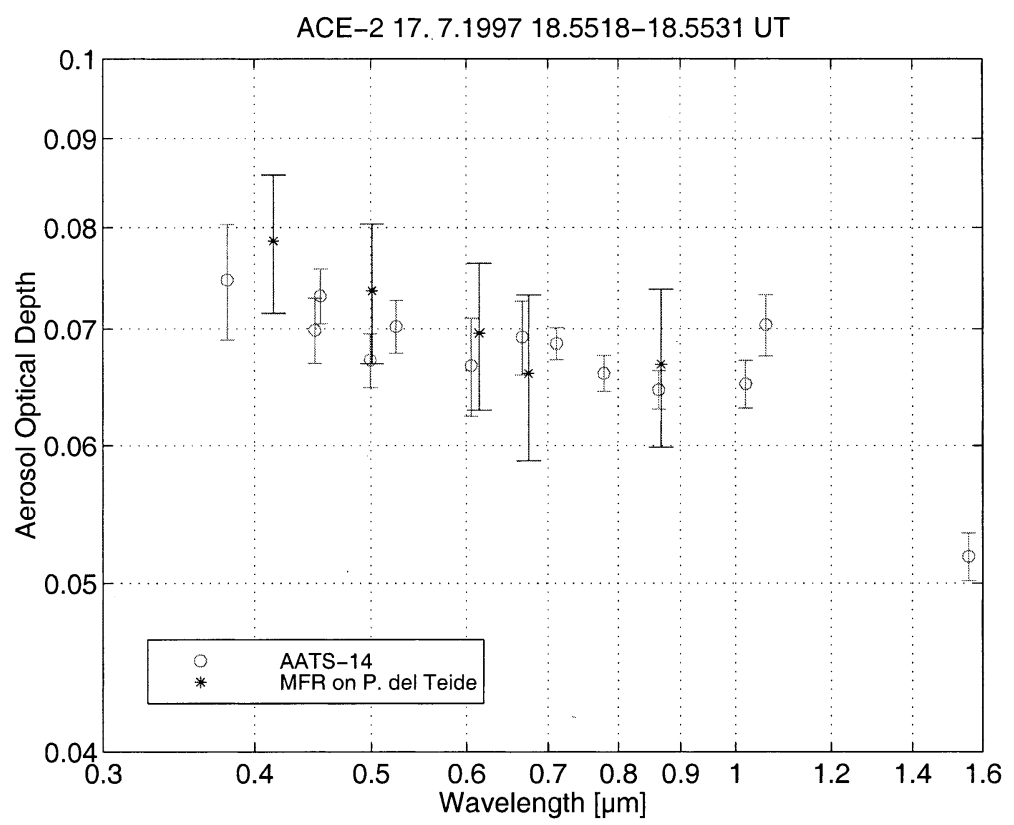

Fig. 21. Spectral AOD from airborne AATS-14 on the Pelican aircraft compared to spectral AOD from groundbased MFR on Teide (3570 m), when Pelican was flying at identical altitude.

Foundation, Office of Naval Research, National Oceanic and Atmospheric Administration, and National Aeronautics and Space Administration, the Max Planck Society, and the European Commission DG XII (Environment and Climate). Acknowledgement is given to the AERONET program for making available CIMEL sunphotometer aerosol optical depth measurements and to the Ozone Processing Team at NASA Goddard Space Flight Center for making available TOMS EP data. We also thank Q. Wang at the Naval Postgraduate School in Monterey, CA, for providing us with differentially corrected Global Positioning System data for the ACE-2 Pelican flights.

\section{REFERENCES}

Anderson, T. L., Covert, D. S., Marshall, S. F., Laucks, M. L., Charlson, R. J., Waggoner, A. P., Ogren, J. A., Caldow, R., Holm, R. L., Quant, F. R., Sem, G. J., Wiedensohler A., Ahlquist, N. A. and Bates, T. S. 1996. Performance characteristics of a high-sensitivity, three wavelength, total scatter/backscatter nephelometer. J. Atmos. Ocean. Tech. 13, 967-986.

Bögel, W. 1977. Neue Näherungsgleichungen für den Sättigungsdruck des Wasserdampfes und für die in der Meteorologie gebräuchlichen Luftfeuchte-Parameter DLR-FB 77-52. Deutsche Forsch.- und Versuchsanst. für Luft- und Raumfahrt, Oberpfaffenhofen.

Bluth, R. T, Durkee, P. A., Seinfeld, J. H., Flagan, R. C., Russell, L. M., Crowley, P. A. and Finn, P. 1996 Center for Interdisciplinary Remotely-Piloted Aircraft Studies (CIRPAS). Bull. Amer. Meteor. Soc. 77, 2691-2699.
Brenguier, J.-L., Chuang, P., Fouquart, Y., Johnson, D. W., Parol, F., Pawlowska, H., Pelon, J., Schüller, L., Schröder, F. and Snider, J. 2000. An overview of the ACE-2 CLOUDYCOLUMN Closure Experiment. Tellus 52B, 815-827.

Brown, B. B. 1997. Remote measurement of aerosol optical properties using the NOAA POES AVHRR and GOES imager during TARFOX. MS Thesis, Naval Postgraduate School, Monterey, CA, $73 \mathrm{pp}$.

Carrico, C. M., Rood, M. J., Ogren, J. A., Neusüss, C., Wiedensohler, A. and Heintzenberg, J. 2000. Aerosol optical properties at Sagres, Portugal during ACE-2. Tellus 52B, 694-715.

Carlson, T. N. and Caverly, R. S. 1977. Radiative characteristics of Saharan dust at solar wavelengths. J. Geophys. Res. 82, 3141-3152.

Clarke, A. D., Porter, J. N., Valero, F. P. J. and Pilwes- 
kie, P. 1996. Vertical profiles, aerosol microphysics, and optical closure during the Atlantic stratocumulus transition experiment: measured and modeled column optical properties. J. Geophys. Res. 101, 4443-4453.

Collins, D. R., Jonsson, H. H., Seinfeld, J. H., Flagan, R. C., Gassó, S., Hegg, D. A., Schmid, B., Russell, P. B., Livingston, J. M., Öström, E., Noone, K. J., Russell, L. M. and Putaud, J. P. 2000. In situ aerosol size distributions and clear column radiative closure during ACE-2. Tellus 52B, 498-525.

D'Almeida, G. A. 1987. On the variability of desert aerosol radiative characteristics. J. Geophys. Res. 92, 3017-3026.

Durkee, P. A., Pfeil, F., Frost, E. and Shema, R. 1991 Global analysis of aerosol particle characteristics. Atmos. Environ. 25A, 2457-2471.

Durkee, P. A., Nielsen, K. E., Smith, P. J., Russell, P. B., Schmid, B., Livingston, J. M., Holben, B. N., Collins, D. R., Flagan, R. C., Seinfeld, J. H., Noone, K. J., Öström, E., Gassó, S., Hegg, D., Russell L. M., Bates, T. S. and Quinn, P. K. 2000. Regional aerosol properties from satellite observations: ACE-1, TARFOX and ACE-2 results. Tellus 52B, 484-497.

Eatough, D. J., Eatough, D. A., Lewis, L. and Lewis, E. A. 1996. Fine particulate chemical composition and light extinction at Canyonlands National Park using organic particulate material concentration obtained with a multisystem, multichannel diffusion denuder sampler. J. Geophys. Res. 101, 19,515-19,531.

Formenti, P., Andreae, M. O. and Lelieveld, J. 2000. Measurements of aerosol optical depth in the North Atlantic free troposphere: results from ACE-2. Tellus 52B, 678-693.

Fouquart, Y., Bonnel, B., Chaoui Roquai, M., Santer, R. and Cerf, A. 1987. Observation of Saharan aerosols: results of ECLATS field experiment. Part 1: optical thicknesses and aerosol size distributions. J. Clim. Appl. Meteor. 26, 28-37.

Gassó, S., Hegg, D. A., Noone, K. J., Covert, D. S., Schmid, B., Russell, P. B., Livingston, J. M., Durkee, P. A. and Jonsson, H. H. 2000. Influence of humidity on the aerosol scattering coefficient and its effect on the upwelling radiance during ACE2. Tellus 52B 546-567.

Gonzalez Jorge, H. and Ogren, J. A. 1996. Sensitivity of retrieved aerosol properties to assumptions in the inversion of spectral optical depths. J. Atmos. Sci. 53, 3669-3683.

Halthore, R. N., Nemesure, S., Schwartz, S. E., Imre, D. G., Berk, A., Dutton, E. G. and Bergin, M. H. 1998 Models overestimate diffuse clear-sky surface irradiance. A case for excess atmospheric absorption. Geophys. Res. Lett. 25, 3591-3594.

Hartley, W. S., Hobbs, P. V., Ross, J. L., Russell, P. B. and Livingston, J. M. 2000. Properties of aerosols aloft relevant to direct radiative forcing off the mid-Atlantic coast of the United States. J. Geophys. Res., in press.

Hegg, D. A., Livingston, J. M., Hobbs, P. V., Novakov, T. and Russell, P. B. 1997. Chemical apportionment of aerosol column optical depth off the mid-Atlantic coast of the United States. J. Geophys. Res. 102, 25,293-25,303.

King, M. D. 1982. Sensitivity of constrained linear inversions to the selection of the Lagrange multiplier J. Atmos. Sci. 39, 1356-1369.

King, M. D., Byrne, D. M., Herman, B. M. and Reagan, J. A. 1978. Aerosol size distributions obtained by inversion of spectral optical depth measurements. J. Atmos. Sci. 35, 2153-2167.

Kotchenruther, R. A., Hobbs, P. V. and Hegg, D. A. 1999. Humidification factors for atmospheric aerosols off the mid-Atlantic coast of the United States. J. Geophys. Res. 104, 2239-2251.

Larson, S. M., Cass, G. R., Hussey, K. J. and Luce, F. 1988. Verification of image-processsing based visibility models. Environ. Sci. Technol. 22, 629-637.

Livingston, J. M., Kapustin, V., Schmid, B., Russell, P. B., Durkee, P. A., Bates, T. and Quinn, P. K. 2000. Shipboard sunphotometer measurements of aerosol optical depth spectra during ACE-2. Tellus 52B, 594-619.

Matsumoto, T., Russell, P. B., Mina, C., Van Ark, W. and Banta, V. 1987. Airborne tracking sunphotometer. J. Atmos. Ocean. Tech. 4, 336-339.

Michalsky, J., Beauharnois, M., Berndt, J., Harrison, L. Kiedron, P. and Min, Q. 1999. $\mathrm{O}_{2}-\mathrm{O}_{2}$ absorption band identification based on optical depth spectra of the visible and near-infrared. Geophys. Res. Lett. 26, $1581-1584$.

Öström, E. and Noone, K. J. 2000. Vertical profiles of aerosol scattering and absorption measured in situ during the north Atlantic aerosol characterization experiment. Tellus 52B, 526-545.

Patterson, E. M., Gilette, D. A. and Stockton, B. H. 1977. Complex index of refraction between 300 and $700 \mathrm{~nm}$ for Saharan aerosols. J. Geophys. Res. 82, 3153-3160.

Putaud, J. P., Van Dingenen, R., Mangoni, M., Virkkula, A., Raes, F., Maring, H., Prospero, J. M., Swietlicki, E., Berg, O. H., Hillamo, R. and Makela, T. Chemical mass closure and origin assessment of the submicron aerosol in the marine boundary layer and the free torposphere at Tenerife during ACE-2. 2000. Tellus 52B, 141-168.

Quinn, P. K., Anderson, T. L., Bates, T. S., Dlugi, R., Heintzenberg, J., von Hoyningen-Huene, W., Kulmala, M., Russell, P. B. and Swietlicki, E. 1996. Closure in tropospheric aerosol-climate research: a review and future needs for addressing aerosol direct shortwave radiative forcing. Contrib. Atmosph. Phys. 69, 547-577.

Raes, F., Bates, T., McGovern, F. and van Liedekerke, M. 2000. The second aerosol chatacterization experiment (ACE-2): general context and main results. Tellus 52B, 111-126.

Remer, L. A., Gassó, S., Hegg, D. A., Kaufman, Y. J. and Holben, B. N. 1997. Urban/industrial aerosol: groundbased sun/sky radiometer and airborne in situ measurements. J. Geophys. Res. 102, 16,849-16,859.

Russell, P. B. and Heintzenberg, J. 2000. An overview of 
the ACE-2 Clear Sky Column Closure Experiment (CLEARCOLUMN). Tellus 52B, 463-483.

Russell, P. B., Hobbs, P. V. and Stowe, L. L. 1999a. Aerosol properties and radiative effects in the US midAtlantic haze plume. An overview of the tropospheric aerosol radiative forcing observational experiment (TARFOX). J. Geophys. Res. 104, 2213-2222.

Russell, P. B., Livingston, J. M., Hignett, P., Kinne, S. Wong, J. and Hobbs, P. V. 1999b. Aerosol-induced radiative flux changes off the United States midAtlantic coast: comparison of values calculated from sunphotometer and in situ data with those measured by airborne pyranometer. J. Geophys. Res. 104, 2289-2307.

Russell, P. B., Livingston, J. M., Dutton, E. G., Puschel, R. F., Reagan, J. A., Defoor, T. E., Box, M. A., Allen, D., Pilewski, P., Herman, B. M., Kinne, S. and Hofmann, D. J. 1993. Pinatubo and pre-Pinatubo optical-septh spectra: Mauna Loa measurements, comparisons, inferred particle size distributions, radiative effects, and relationsship to lidar data. J. Geophys. Res. 98, 22,969-22,985.

Schmeling, M., Russell, L. M., Erlick, C., Collins, D. R., Flagan, R. C., Seinfeld, J. H., Jonsson, H. H., Wang, Q., Kregsamer, P. and Streli, C. 2000. Aerosol particle chemical characteristics measured from aircraft in the lower troposphere during ACE-2. Tellus 52B, 185-200.

Schmid, B. and Wehrli, C. 1995. Comparison of sun photometer calibration by Langley technique and Standard lamp. Appl. Opt. 34, 4500-4512.

Schmid, B., Thome, K. J., Demoulin, P., Peter, R. Mätzler, C. and Sekler, J. 1996. Comparison of modeled and empirical approaches for retrieving columnar water vapor from solar transmittance measurements in the 0.94 micron region. J. Geophys. Res 101, 9345-9358.

Schmid, B., Mätzler, C., Heimo, A. and Kämpfer, N. 1997. Retrieval of optical depth and size distribution of tropospheric and stratospheric erosols by means of sun photometry. IEEE Trans. Geosc. Rem. Sens. 35, 172-182.

Schmid, B., Spyak, P. R., Biggar, S. F., Wehrli, C., Sekler, J., Ingold, T., Mätzler, C. and Kämpfer, N 1998. Evaluation of the applicability of solar and lamp radiometric calibrations of a precision sun photometer operating between 300 and $1025 \mathrm{~nm}$. Appl. Opt. 37, 3923-3941.

Schmid, B., Michalsky, J., Halthore, R., Beauharnois, M., Harrison, L., Livingston, J., Russell, P., Holben, B., Eck, T. and Smirnov, A. 1999. Comparison of aerosol optical depth from four solar radiometers during the fall 1997 ARM intensive observation period. Geophys. Res. Lett. 17, 2725-2728.

Seinfeld, J. H. and Pandis, S. N. 1998. Atmospheric chemistry and physics. New York: Wiley-Interscience.

Smirnov, A., Holben, B. N., Slutsker, I., Welton, E. J. and Formenti, P. 1998. Optical properties of Saharan dust during ACE-2. J. Geophys. Res. 103, 28,079-28,092.

Stern, A. C. 1977. Air pollution, vol. IV, 3rd edition Academic Press, New York, p. 103.

Tang, I. N. 1996. Chemical and size effects of hygroscopic aerosols on light scattering coefficients. J. Geophys. Res. 101, 19,245-19,250.

Tang, I. N. and Munkelwitz, H. R. 1994. Water activities, densities, and refractive indices of aqueous sulfates and sodium nitrate droplets of atmospheric importance. J. Geophys. Res. 99, 18,801-18,808.

Tang, I. N, Tridico, A. C. and Fung, K. H. 1997. Thermodynamic and optical properties of sea salt aerosols. J. Geophys. Res. 102, 23,269-23,275.

Tanré, D., Kaufman, Y. J., Herman, M. and Mattoo, S. 1997. Remote sensing of aerosol properties over oceans using MODIS/EOS spectra radiances. J. Geophys. Res. 102, 16,971-16,988.

Tegen, I. and Fung, I. 1994. Modelling of mineral dust in the atmosphere: sources, transport, and optical thickness. J. Geophys. Res. 99, 22,897-22,914.

Volz, F. E. 1973. Infrared optical constants of ammonium sulfate, Sahara dust, volcanic pumice, and flyash. Appl. Opt. 12, 564-568.

Welton, E. J., Voss, K. J., Gordon, H. R., Maring, H., Smirnov, A., Holben, B. N., Schmid, B. Livingston, J. M., Russell, P. B., Durkee, P. A., Formenti, P. and Andreae, M. O. 2000. Ground-based lidar measurements of aerosols during ACE-2: lidar description, results, and comparisons with other ground-based and airborne measurements. Tellus 52B, 636-651. 